\title{
Potential of Advanced Microwave Sounding Unit to identify precipitating systems and associated upper-level features in the Mediterranean region: Case studies
}

\author{
B. M. Funatsu, ${ }^{1}$ C. Claud, ${ }^{1}$ and J.-P. Chaboureau ${ }^{2}$ \\ Received 30 November 2006; revised 15 May 2007; accepted 13 June 2007; published 15 September 2007.
}

[1] The potential of the Advanced Microwave Sounding Unit (AMSU) observations to identify and characterize precipitating systems in the Mediterranean region is explored. Single channels or combination channels from AMSU-A are used to detect and locate upper level potential vorticity anomalies that are often associated with intensification of surface low systems and occurrence of extreme events, while AMSU-B data is used to detect precipitating areas. The motivation for the approach presented here is the direct use of satellite data as an alternative for reanalysis data sets for climatological studies of Mediterranean lows, without relying on retrieval algorithms. AMSU-A channel 8 was found to be more suitable to identify upper level southward intrusions of stratospheric air than the difference of channels 7 and 5, which detects only vertically deep intrusions. A combination of AMSU-B channels 3 and 5 is able to discriminate moderate to strongly precipitating areas with good agreement with Tropical Rainfall Measuring Mission (TRMM) derived products and independent ground-based data. A more stringent condition based on differences of channels 3 to 5 was found to be useful to detect deep convective clouds. We demonstrate the applicability of AMSU to detect upper level features and precipitating systems for selected case studies of extreme precipitation in the Mediterranean region. These tools will allow us to form a climatology of moderate to strongly precipitating systems, and to investigate their relationship with upper level features that may be precursors of extreme events, and to establish a typology of the precipitating systems in the Mediterranean region.

Citation: Funatsu, B. M., C. Claud, and J.-P. Chaboureau (2007), Potential of Advanced Microwave Sounding Unit to identify precipitating systems and associated upper-level features in the Mediterranean region: Case studies, J. Geophys. Res., 112, D17113, doi:10.1029/2006JD008297.

\section{Introduction}

[2] The Mediterranean basin is a region of frequent cyclonic activity. The distribution of cyclones over this area is complex, with orography and latent heat release at the sea surface (local forcing) playing important roles at times, but the intensity of the cyclonic activity is to a large extent controlled by synoptic perturbations from midlatitudes. These processes are commonly characterized by mid and upper-tropospheric southward air mass intrusions and tropopause foldings, often associated with potential vorticity (PV) structures and jet streaks [e.g., Appenzeller and Davies, 1992; Appenzeller et al., 1996; Liniger and Davies, 2003]. While there have been several studies aiming at characterizing the sub-areas of cyclogenesis, the seasonality

\footnotetext{
${ }^{1}$ Laboratoire de Meteorologie Dynamique/IPSL, Ecole Polytechnique, Palaiseau, France.

${ }^{2}$ Laboratoire d'Aérologie, CNRS/UPS, Toulouse, France.

Copyright 2007 by the American Geophysical Union. 0148-0227/07/2006JD008297
}

and the generation mechanisms of Mediterranean systems, they mostly rely on reanalyses and/or simulations [e.g., Alpert et al., 1990; Trigo et al., 1999]. Alternatively, Chaboureau and Claud [2006] performed a climatology of cloud systems and upper level disturbances in the Mediterranean based on 8.5 years of TIROS Operational Vertical Sounder (TOVS) satellite data, and showed that cloud systems in the Mediterranean have distinct seasonal characteristics, both in terms of size and relationship with upper level dynamics. They also showed that for about $30 \%$ of cloud systems in the winter there was an upper level anomaly upstream. The frequency was reduced to $26 \%$ in the spring, and only $7 \%$ in fall, though for October the number of cases where an upper level anomaly was present was of $23 \%$. The importance of the upper level feature to the development of strong storms was furthermore demonstrated for the Alpine region, in which precipitating cloud systems were identified based on the precipitation climatology of Frei and Schär [1998]. They found that cloud systems that yielded precipitation larger than $50 \mathrm{~mm} /$ day showed a typical baroclinic configuration with warm and 
nearly N-S elongated upper level temperature anomaly upstream. These results agree with those of Massacand et al. [1998] who showed that narrow, vertically deep and elongated PV streamers are distinctive precursors of storms in the Alpine region. However, two limitations of the study of Chaboureau and Claud [2006] were the rather poor spatial resolution of the Microwave Sounding Unit (MSU), one of TOVS radiometers, compared to the sub-synoptic size of Mediterranean storms and consequent inability to detect precipitation using this data set.

[3] In this study we explore the Advanced Microwave Sounding Unit (AMSU) satellite observations to study climatological features in the Mediterranean region. The AMSU instrument has been collecting data in the microwave (MW) frequencies onboard of NOAA-15, 16, and 17 polar-orbiting satellites starting in 1998, 2000, and 2002, respectively. The main advantage of the MW remote sensing over infrared and visible channels is that MW radiation penetrates clouds, and is sensitive to atmospheric temperature and moisture, cloud liquid water, cloud ice water and rain [Kidder et al., 2000]. Also, it has improved horizontal and spectral (hence vertical) resolutions compared to MSU, with frequencies specifically suited for optimal moisture and temperature profile retrievals. Therefore some of the precipitation features that were not captured using previous instruments of TOVS may be detected using this data set.

[4] The motivation for this study is to explore the potential of direct use of AMSU without relying on inversion algorithms to detect both upper-level features and precipitation. Our study utilizes AMSU data to (i) identify moderate to strongly precipitating systems in the Mediterranean region, and (ii) identify whether there is a signature of upper-level precursors to these storms that is detectable in the AMSU measurements. These goals are inter-related, but each stands by itself because we do not know a priori whether the occurrence of one implies on the presence of the other (either rain or upper level feature). Another motivation for this study is to examine the concomitant temporal evolution of these elements, with a further aim to form a climatological picture of precipitating systems in the Mediterranean, and to investigate their relation with largescale patterns. Such climatology, formed through direct observations, can then be compared with climatological studies using reanalysis data. We seek to provide a typology of precipitating cyclones for each season (earlier studies have highlighted the strong seasonal variability), to determine the proportion of lows for which the dynamics is dominated by the upper-level features and to examine the potential links between precipitation and the upper-level dynamics. In this study, the potential of AMSU is investigated by putting special emphasis on selected cases that presented severe precipitation and are pertinent to the CYclogenèse et PRécipitation Intenses en région Méditerranéenne (CYPRIM) and MEDiterranean EXperiment (MEDEX) projects. These selected cases are spatially distributed so that both western and eastern Mediterranean are covered. In addition to case studies, it was desirable to choose a period which would provide a significant sample of rain, heavy rain and periods without rain, in order to determine rain and convection detection thresholds and evaluate them against false positives. We settled for choosing one month within the fall season, when there is historically a larger number of occurrences of heavy rainfall [e.g., Fita et al., 2006]. NOAA-16 data for the entire month of November 2001 was thus used, covering the whole of the Mediterranean basin. This approach provides results that are thus suitable for the entire region. The selected cases are:

[5] 1. Algerian case: 09-10 November 2001$262 \mathrm{~mm} / 24 \mathrm{~h}$ registered in Algiers, and $240 \mathrm{~mm} / 24 \mathrm{~h}$ in the Balearic Islands (Spain). Floods, extreme winds and gusts caused extensive damage and loss of lives and property in Algeria, Morocco and Balears [Tripoli et al., 2005; Moore et al., 2005; Söhne et al., 2006; Argence et al., 2006].

[6] 2. Israel Case: 03-05 December 2001 - intense precipitation and floods, associated with a Cyprus cyclone [Alpert et al., 1995; Alpert et al., 2004; Krichak et al., 2004].

[7] 3. Nîmes-Marseille Storm: 08-09 September 2002 - A mesoscale convective system caused heavy rainfall (accumulated precipitation of $690 \mathrm{~mm} / 24 \mathrm{~h}$ at some locations), flash floods, and both human and economical loss in the Gard Region, France [Delrieu et al., 2005].

[8] 4. Antalya Case: 05-06 December 2002 - intense precipitation $(230 \mathrm{~mm} / 24 \mathrm{~h})$ and floods [Kotroni et al., $2006]$.

[9] 5. Rhône-Herault Storm: 01-03 December 2003 - two frontal systems yielded heavy rainfall, with accumulated precipitation of $200 \mathrm{~mm} / 24 \mathrm{~h}$ (total of $300 \mathrm{~mm}$ for this event).

[10] 6. Herault-Nîmes storm: 05-09 September 2005. Severe floods in Nîmes, Montpellier and many villages. Heavy economical losses, with disruption of business, communication and transportation, as well as evacuation of thousands of residents of affected areas.

[11] The paper is structured as follow: Section 2 describes AMSU data and necessary corrections of limb effect. In section 3 the potential of AMSU to identify upper-level thermal disturbances is explored while detection of precipitation is presented in section 4 . To further demonstrate the applicability of the methods described in the preceding sections, two heavy rainfall events are described in section 5. Finally, section 6 contains a summary of the main conclusions.

\section{Data}

[12] AMSU is a cross-scanning instrument which consists of two modules: (i) AMSU-A which has channels in the molecular Oxygen frequencies $(50-58 \mathrm{GHz})$ and is mainly designed for atmospheric temperature profile retrieval, and (ii) AMSU-B which has 5 channels, three of which have frequencies near $183 \mathrm{GHz}$ (water vapor absorption line), and is designed for optimal moisture retrieval. Furthermore, both modules have microwave window channels. Both AMSU-A and B have swath width of approximately $2300 \mathrm{~km}$; the near nadir instantaneous field of view (FOV) of AMSU-A is $48 \mathrm{~km}$ (30 measurements spanning $\pm 48^{\circ}$ ) while AMSU-B has a near nadir resolution of $16 \mathrm{~km}$ (90 measurements). Table 1 lists the channels for each instrument and their respective frequencies, and Figure 1 shows the weighting functions distribution (from Goldberg et al., 2001) for AMSU-A channels 3 to 14. Information provided by the combination of microwave window (mainly by the surface and hydrometeors) and absorption $\left(\mathrm{O}_{2}\right.$ and $\mathrm{H}_{2} \mathrm{O}$ ) channels makes AMSU data useful for yielding 
Table 1. Frequencies and Band Width of AMSU-A and B Channels $^{\mathrm{a}}$

\begin{tabular}{|c|c|c|c|c|c|}
\hline \multicolumn{3}{|c|}{ AMSU-A } & \multicolumn{3}{|c|}{ AMSU-B } \\
\hline $\begin{array}{l}\text { Channel } \\
\text { Number }\end{array}$ & $\begin{array}{c}\text { Center } \\
\text { Freq, GHz }\end{array}$ & $\begin{array}{c}\text { Bandwidth, } \\
\mathrm{MHz}\end{array}$ & $\begin{array}{l}\text { Channel } \\
\text { Number }\end{array}$ & $\begin{array}{c}\text { Center } \\
\text { Freq, GHz }\end{array}$ & $\begin{array}{c}\text { Bandwidth, } \\
\mathrm{MHz}\end{array}$ \\
\hline $1^{w}$ & 23.80 & 251 & $1^{w}$ & 89 & 5000 \\
\hline $2^{w}$ & 31.40 & 161 & $2^{w}$ & 150 & 4000 \\
\hline 3 & 50.30 & 161 & 3 & $183 \pm 1$ & 1000 \\
\hline 4 & 52.80 & 380 & 4 & $183 \pm 3$ & 2000 \\
\hline 5 & $53.59 \pm 0.115$ & 168 & 5 & $183 \pm 7$ & 4000 \\
\hline 6 & 54.40 & 380 & & & \\
\hline 7 & 54.94 & 380 & & & \\
\hline 8 & 55.50 & 310 & & & \\
\hline 9 & 57.29 (fo) & 310 & & & \\
\hline 10 & fo \pm 0.217 & 76 & & & \\
\hline 11 & fo $\pm 0.322 \pm 0.048$ & 34 & & & \\
\hline 12 & fo $\pm 0.322 \pm 0.022$ & 15 & & & \\
\hline 13 & fo $\pm 0.322 \pm 0.010$ & 8 & & & \\
\hline 14 & fo $\pm 0.322 \pm 0.004$ & 3 & & & \\
\hline $15^{w}$ & 89.00 & 2000 & & & \\
\hline
\end{tabular}

${ }^{\mathrm{a}}$ The superscript $w$ denoted a window channel.

surface and atmospheric products and observing a variety of atmospheric phenomena, e.g., tropical cyclones [Kidder et al., 2000; Brueske and Velden, 2003], polar lows [Moore and Vonder Haar, 2003], cloudiness and precipitation [Burns et al., 1997; Greenwald and Christopher, 2002; Bennartz et al., 2002; Hong et al., 2005]. Retrieval of precipitation has been derived from AMSU observation alone or with other information [e.g., Weng et al., 2003; Liu and Weng, 2003; Kongoli et al., 2003; Qiu et al., 2005]. Assimilation of AMSU data in numerical models have been demonstrated to improve forecast skills, as shown by $Z h u$ et al. [2002], Zhao et al. [2005], Prigent et al. [2005], Langland [2005], and Le Marshall et al. [2006], among others.

[13] In this study we use data from NOAA-16 and 17 only, since early NOAA-15 data had problems with antenna interference [Mo, 1999] during 1998-1999. Although this problem was corrected subsequently, scan asymmetries with respect to angle of view in NOAA-15 AMSU-B data are large [Buehler et al., 2005] while AMSU-B data from NOAA-16 and 17 have small asymmetries, comparable to the instrument noise. NOAA-15 and 16 AMSU-A data also present scan asymmetries, but the effect is mostly significant in the window channels $(23.8,31.4,50.3$, and $89 \mathrm{GHz})$ which are not used in this study, while for the remaining channels this effect is attenuated by the presence of the atmosphere [Weng et al., 2003].

[14] AMSU-A data must be furthermore corrected for the limb effect, which arises from the fact that the satellite scans a thicker layer in the atmosphere as the field of view departs from the nadir position. This represents effectively a shift in the weighting function to a higher altitude, yielding an artificial brightness temperature (BT) cooling (tropospheric channels) or warming (stratospheric channels) at larger field of view, as shown in Figure 1. The superposition of subsequent orbits and identification of coherent structures is therefore complicated, e.g., Figure 10 of Goldberg et al. [2001]. Several methods have been proposed to correct the limb effect, based on statistical [Wark, 1993], physical [Goldberg and Fleming, 1995], and physico-statistical [Goldberg et al., 2001] constraints, and they have been shown to reduce this effect to noise level accuracy. Here we adjust AMSU-A BTs using coefficients derived from the Radiative Transfer for TIROS Operational Vertical sounder (RTTOV) code version 8.5 [Saunders et al., 2005], and based on the case studies listed in section 1. RTTOV is able to simulate realistically the BT in the MW used in AMSU instrument [Bauer et al., 2006].

[15] Figure 2a shows the RTTOV simulated BT biases between the angle of view and nadir for each channel of AMSU-A, for a specific time, while Figures $2 b$ and $2 c$ show the associated standard deviation for window and atmospheric channels, respectively. These biases in the BTs can be large (Figure 2a), e.g, $-10 \mathrm{~K}$ for channel 7, and $-13 \mathrm{~K}$ for channels 5 and 6 . Window channels and lowermost tropospheric channels (1-4 and 15) present larger variability than upper tropospheric and stratospheric channels, the latter having a standard deviation up to $3 \mathrm{~K}$ only. The source of the variability can be the differences between sea and land as well as latitude variation. Another source of variability not included above is time related variation, which should also be considered.

[16] In this study we will use channels 5,7 , and 8 only, because they have weighting functions peaking in the mid to upper troposphere and are useful to detect upper level PV signatures, as further explained in the next section. Figure 3 shows the latitudinal variation of the standard deviation of the BT for the average of beam positions 15 and 16 (nearnadir) based on 150 NOAA-16 overpasses in the month of November 2001 for channels 5, 7, and 8. Their standard deviation increases with latitude, with averaged values of $2.6,1.4$, and $1.9 \mathrm{~K}$, respectively. In contrast, the largest standard deviation of the bias relative to the nadir position

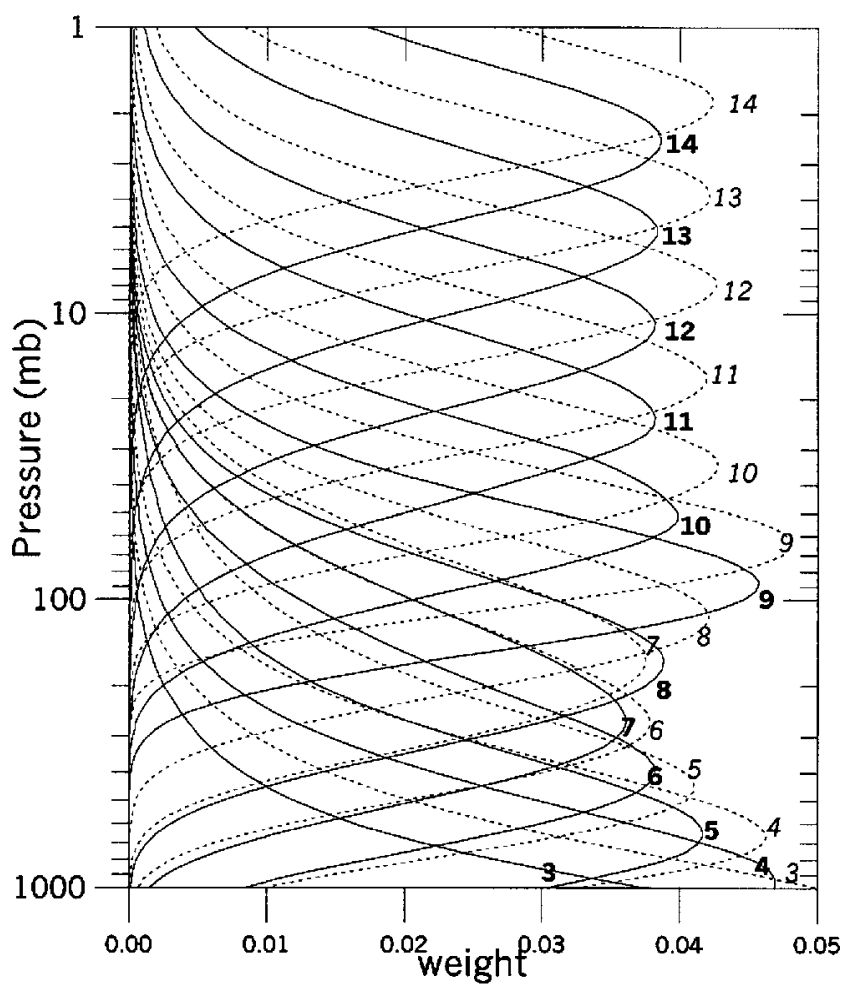

Figure 1. Weighting functions for the AMSU-A temperature-sounding channels (3-14) at nadir (solid) and maximum field of view ( $\sim 48^{\circ}$; dashed). From Goldberg et al. [2001]. 

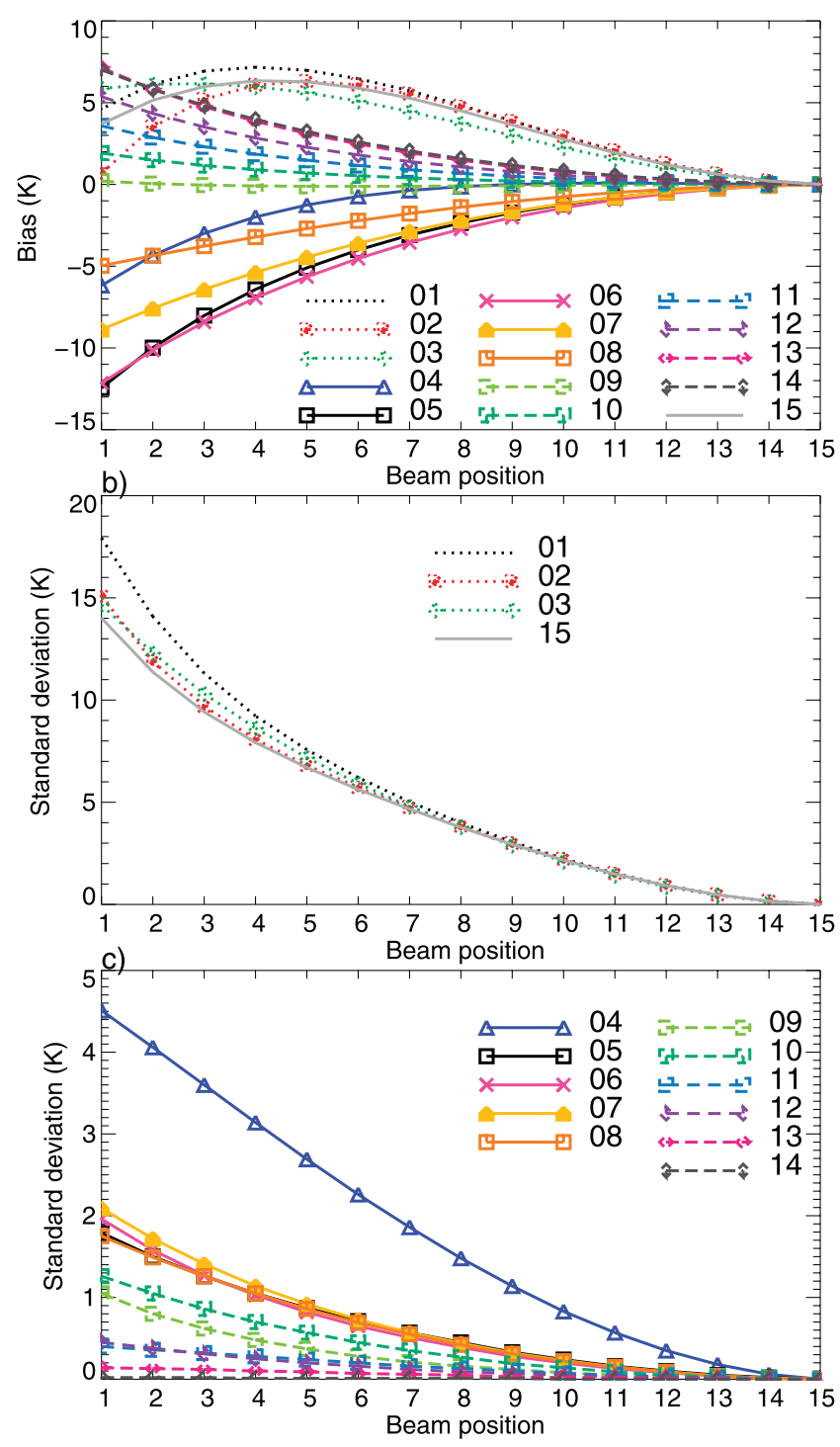

Figure 2. RTTOV derived BTs (a) average bias relative to the nadir position, and associated standard deviation for (b) window and (c) atmospheric channels for AMSU-A as a function of angle of view, at 00 UTC 10 November 2001. Only the first half number of beams are shown as the asymmetry effect is small.

calculated for each of these channels are 1.7, 2.2, and $1.6 \mathrm{~K}$, respectively (Figure 2c). Except for channel 7, the standard deviation of the bias is smaller than the BT variability caused by physical features. For channel 7, the errors are large at largest field of views (4 farthest) but are on average equivalent to the observed BT variability for the majority of beam positions.

[17] When comparing the bias of AMSU-A channel 8 simulated BTs relative to the nadir for 6 arbitrarily chosen days (one for each case study) we found that the biases are not strongly time-dependent (Figure $4 \mathrm{a}$ ), and vary less than $1 \mathrm{~K}$ for different dates. We found, however, that there is a significant variation with latitude (Figure $4 b$ ) within the same day, with bias increasing (decreasing in magnitude) from $-9 \mathrm{~K}$ at around $10^{\circ} \mathrm{N}$ to $-3 \mathrm{~K}$ at around $60^{\circ} \mathrm{N}$. Therefore since the latitudinal dependency of the BT bias is much larger than its temporal dependency, we apply a single set of (latitude dependent) coefficients to correct for the limb effect to all cases.

[18] In addition, the influence of surface in the BT for channel 5 (and to a lesser extent for channels 7 and 8), yields different sets of coefficients for land and ocean. Figure 5 shows the average bias for land and for sea, and their average, for channels 5,7 , and 8 , as a function of beam position. In general, the bias for the land are larger than for the sea. The maximum differences between land and sea coefficients are of about $3 \mathrm{~K}$ for channel $5,1 \mathrm{~K}$ for channel 7 , and lesser than $1 \mathrm{~K}$ for channel 8 . These differences are larger than the estimated instrument noise [see, e.g., Goldberg et al., 2001, Figure 8] therefore they should be accounted for. However, for sake of simplicity we choose to use a single (latitude dependent) set of averaged coefficients for both sea and land.

[19] For AMSU-B, Greenwald and Christopher [2002] report a depression of up to $5 \mathrm{~K}$ due to limb effect in NOAA15 AMSU-B channel 3, but no further documentation of limb effect or its correction for AMSU-B was found. Therefore for module B the data was used without applying any correction.

[20] In order to identify coherent structures in the AMSU-A images we compare them with ERA-40 reanalysis [Uppala et al., 2005] potential vorticity (PV) fields. For rain determination, we use the water vapor frequency channels of AMSU-B, i.e., channels 3 to 5. We choose to explore these channels (in contrast to channels 1 and 2 which are commonly used for rain retrieval) because they are less affected by the underlying surface [e.g., Deeter and Vivekanandan, 2005], and more sensitive to frozen hydrometeors and therefore useful to detect cold clouds. We use mainly the Tropical Rainfall Measuring Mission (TRMM) 3B42 3-hourly accumulated precipitation product for validation of rain detection. Additional precipitation measurements were used from both Météo-France Séries Quotidiennes de Référence (SQR) database [Moisselin et al., 2002] and radar-derived and rain gauge network data from the

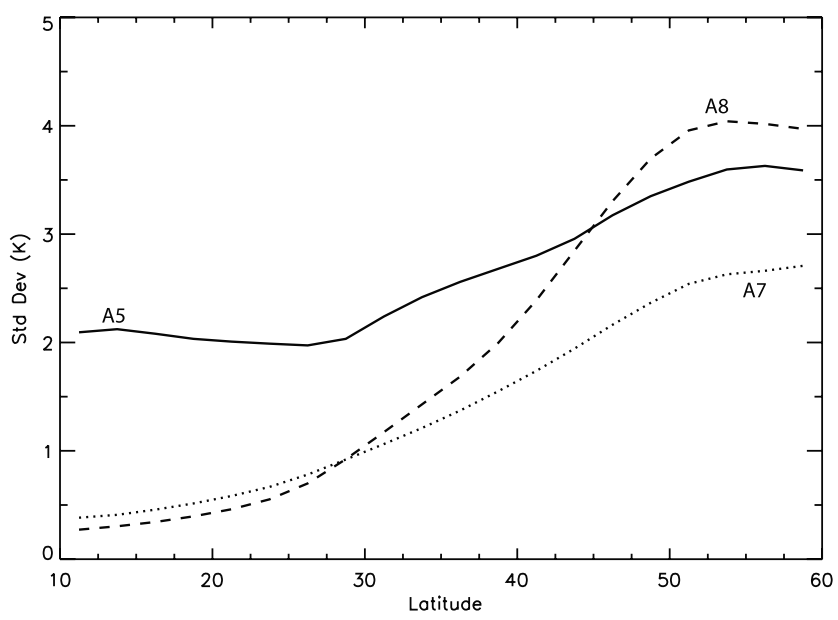

Figure 3. Latitudinal variation of the standard deviation of BT averaged for beam positions 15 and 16 (near-nadir) for AMSU-A5 (solid), A7 (dotted) and A8 (dashed). The standard deviation was calculated based on 150 NOAA-16 orbits in November 2001. 
(a)

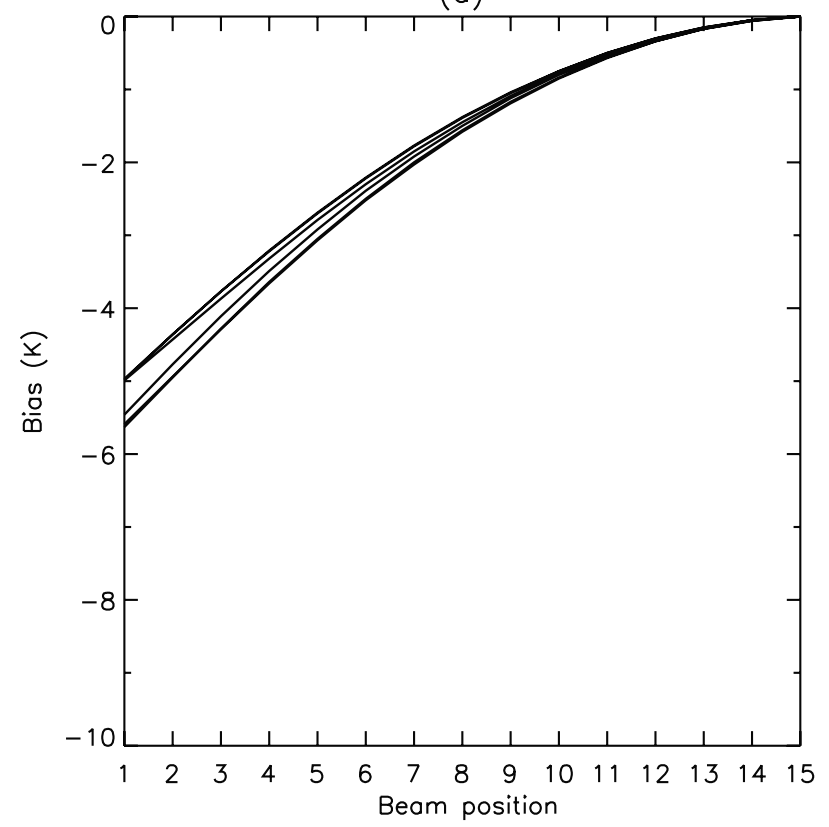

(b)

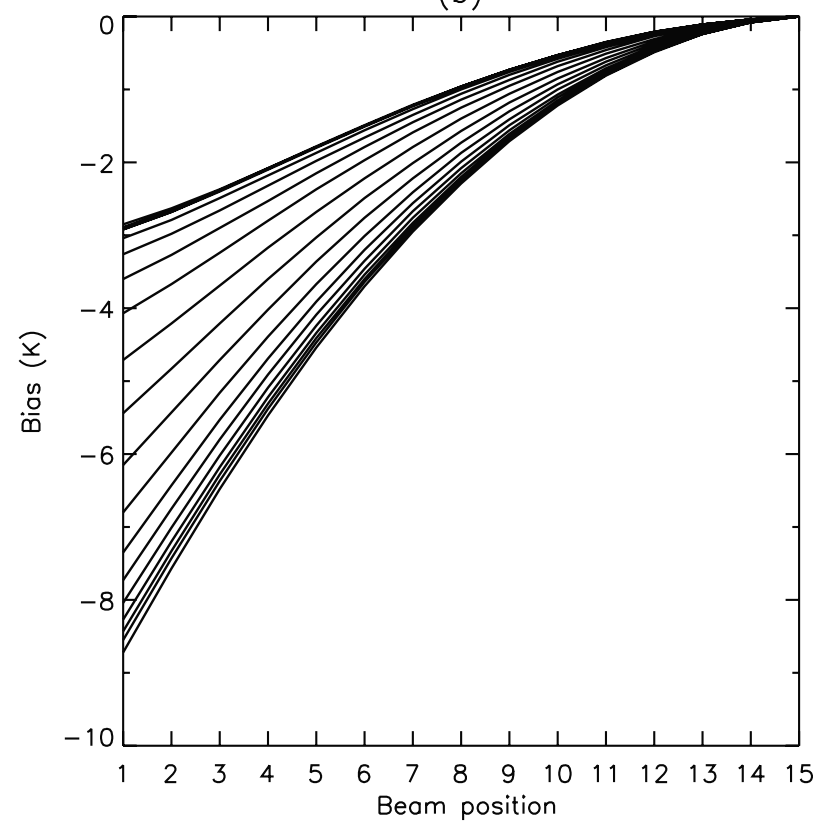

Figure 4. RTTOV derived BT bias for AMSU-A8 for (a) 6 arbitrary dates averaged over all latitudes, and (b) $202.5^{\circ}$ latitude bins, from $10^{\circ}$ to $60^{\circ} \mathrm{N}$ on 12 UTC 8 September 2002. Largest bias correspond to the lowest latitude.

Cévennes-Vivarais Mediterranean Hydrometeorological Observatory (OHM-CV; Delrieu et al., 2005), and for the case of Algiers (1), accumulated rainfall data from several Meteorological Services. SQR data set provides homogeneous series of rainfall data (among other parameters), however the spatial coverage of stations is limited to France and is not uniform. One shortcoming of using TRMM data is that they are not completely independent of AMSU-B, since the rain calculating algorithm for TRMM combines active and passive microwave observations to improve infrared estimates of precipitation. However, because of the limited spatial coverage of the ground stations, allied to the different nature of the interpretation of satellite data and accumulated precipitation at stations (instantaneous vs. accumulated), we argue that as a first step, the above comparison using TRMM data is worthwhile.

\section{Identifying Upper Level Thermal Disturbances Using AMSU-A}

\subsection{Methodology}

[21] Figure 6 shows $\mathrm{PV}$ at $250 \mathrm{hPa}$ and mean sea level pressure for one day of each of the case studies considered (section 1), as well as the cross section of PV and PV anomaly relative to a one-month mean (i.e., November 2001 mean for case 1, December 2002 for case 2, etc.). PV anomalies are shown here to emphasize the extent and "strength" of the intrusion. All cases have in common the presence of an upper level PV "trough", with deep horizontal and vertical intrusion. The cross-sections show that the $2 \mathrm{PVU}$ contour reaches nearly $400 \mathrm{hPa}$ for all cases. These stratospheric intrusions have a corresponding anomaly of +1 PVU or higher, with the strongest positive $\mathrm{PV}$ anomaly concentrated around $250 \mathrm{hPa}$. Because of their stratospheric origin and their downward vertical penetra- tion, the corresponding thermal signal of a intrusion is a warm anomaly, i.e., increased temperature. This is partially due to adiabatic warming as the air descends (compression) and this effect is analogous to the warming observed in the core of tropical cyclones as the air subsides in the center

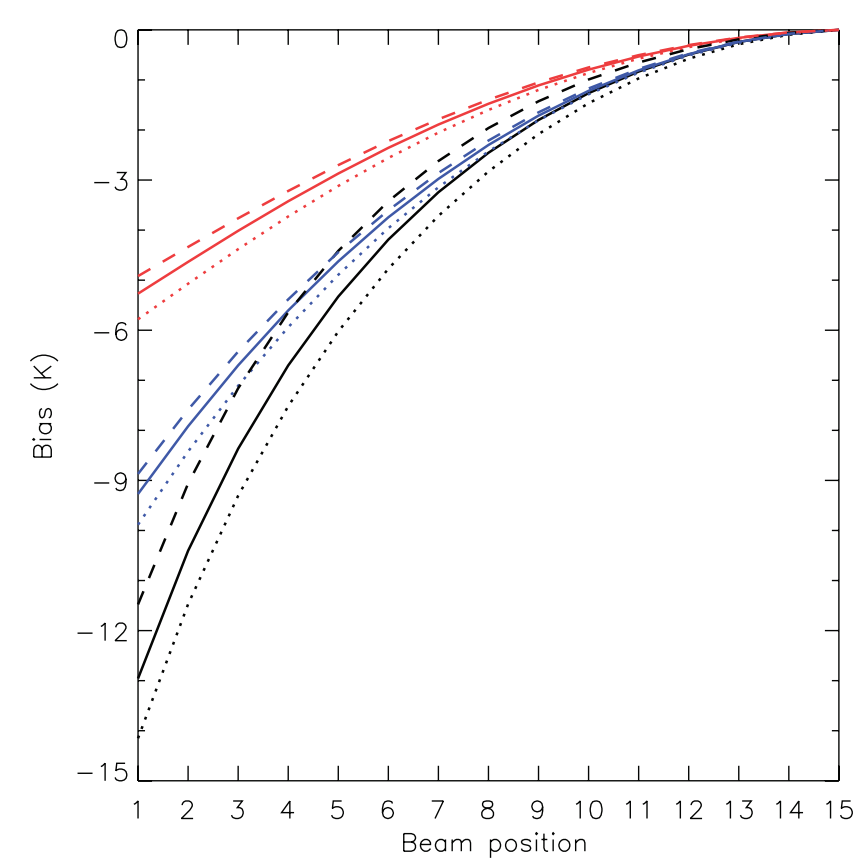

Figure 5. RTTOV derived BT bias for AMSU-A channels 5 (black), 7 (blue) and 8 (red), for land (dotted), sea (dashed), and average of land and sea (solid). The curves are averages over 6 arbitrary days chosen from the case studies listed in section 1 . 

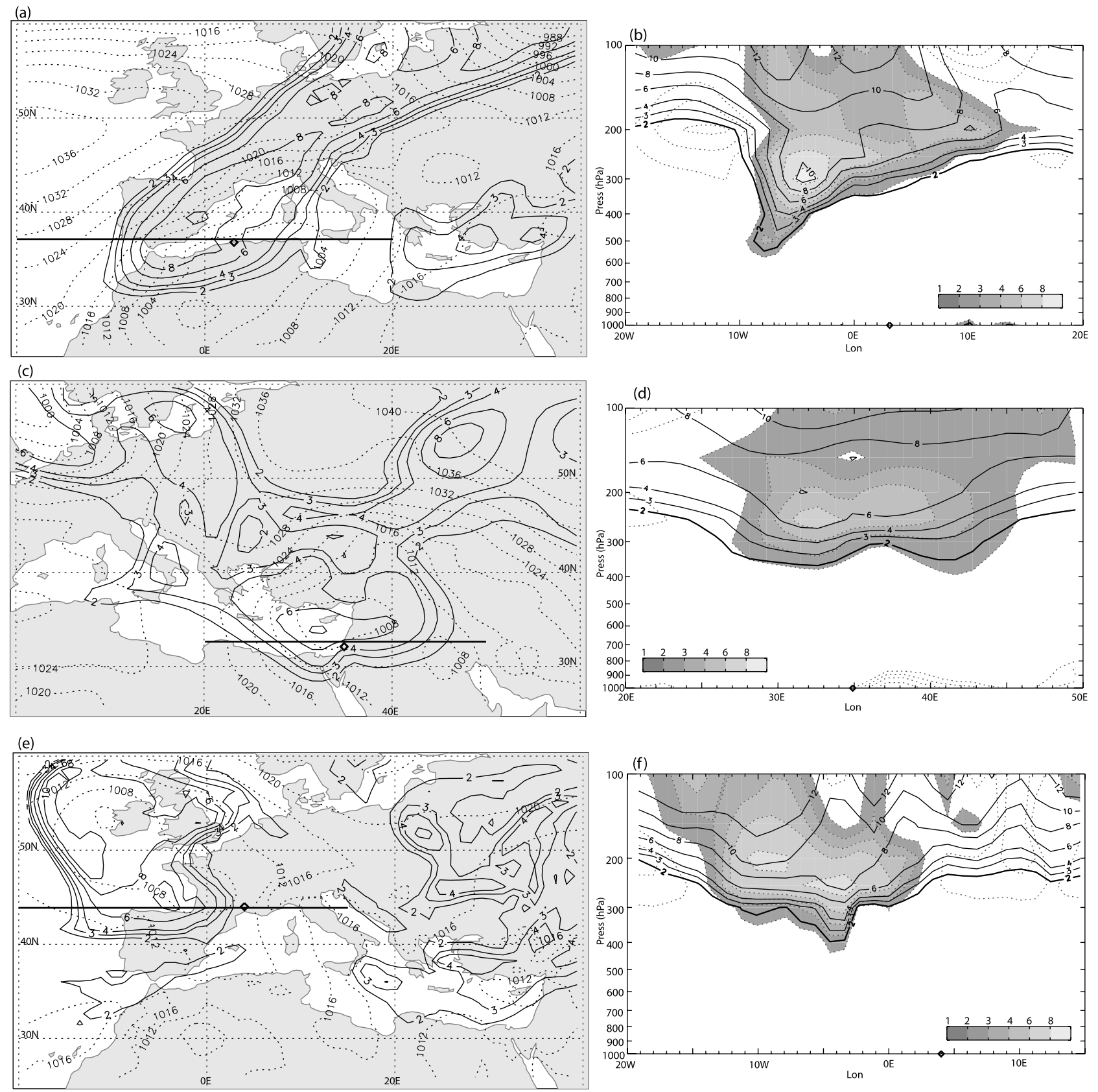

Figure 6. Left column: Potential vorticity at $250 \mathrm{hPa}$ (thick dark; 2, 3, 4, 5, 6, 8 PVU) and mean sea level pressure (dotted; contours every $4 \mathrm{hPa}$ ). Right column: cross section of PV (solid contours) and PV anomaly relative to a monthly mean (dotted with positive PV anomaly shaded; contours of $\pm 1,2,3,4,6$, 8 PVU). (a), (b) 00 UTC 10 November 2001, diamond mark at Algiers $\left(36.8^{\circ} \mathrm{N} 3.1^{\circ} \mathrm{E}\right),(\mathrm{c})$, (d) $12 \mathrm{UTC}$ 4 December 2001, Tel Aviv (32.1 ${ }^{\circ} \mathrm{N} 34.9^{\circ}$ E) (e), (f) 00 UTC 9 September 2002, near Nîmes-Marseille

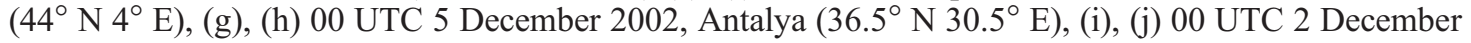
2003, and (k), (l) 00 UTC 7 September 2005 both with marks at $44^{\circ} \mathrm{N} 4^{\circ}$ E. PV and mean sea level pressure from ERA-40 reanalysis for dates before September 2002; for dates in and after September 2002 both fields are from the operational ECMWF analyses. Position of cross section shown in bold line.

of the storm, e.g., Kidder et al. [2000]. In Chaboureau and Claud [2006] study, cloud systems and the upper level thermal structures were identified using atmospheric parameters derived from TOVS by a complex inversion algorithm relying on a pattern recognition approach. Here we seek for an alternative identifier of upper level disturbances that would be available in order to be used both in real time and for climatological purposes. This is possible due to the improved vertical resolution of AMSU compared to TOVS. Figure 1 shows that channels 2 to 6 sample the lower to mid troposphere, and their BTs are susceptible to the effects of precipitation, because both solid and liquid water droplets scatter (and hence reduce) the upwelling radiation. Channels 7 to 9 have weighting functions peaking 

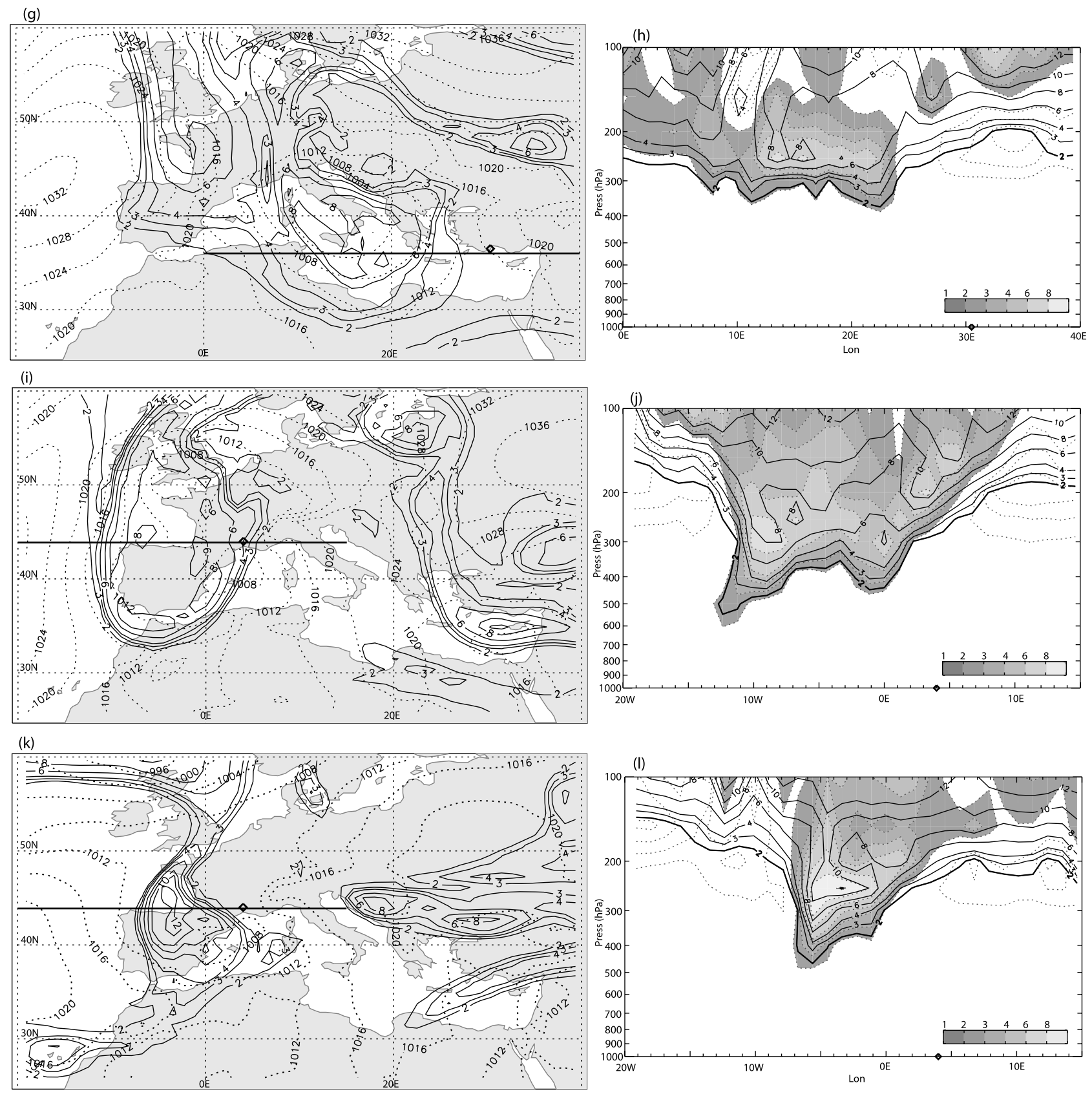

Figure 6. (continued)

at higher altitudes and the scattering effect of precipitation is much reduced or non-existent, making them suitable candidates to demonstrate the upper tropospheric warming due to a PV intrusion. A first choice to consider is channel 8 (hereafter, A8) since its weighting function maximizes around $200 \mathrm{hPa}$, sampling the upper troposphere/lower stratosphere. An alternative option is to examine the difference of channels, e.g., channel 7 minus 5 (hereafter A7m5). This way, the lower troposphere part of the signal is removed, with the further advantage of mitigating the impact of sea-land contrast in the limb-correction.

\subsection{Results}

[22] Figure 7 shows limb-corrected $\mathrm{A} 8$ and $\mathrm{A} 7 \mathrm{~m} 5$, and $250 \mathrm{hPa} \mathrm{PV}$ at the nearest hour, for cases 1 to 6 . All cases except case 2 show PV greater than 6 PVU intruding southwards (see also Figure 6). Case 2 shows a zonally elongated area of PV greater than 6 PVU to the north of the affected area.

[23] In general, both $\mathrm{A} 8$ and $\mathrm{A} 7 \mathrm{~m} 5$ are able to detect a warm core in the vicinity or nearly coincident with high PV. Careful examination of these figures and their sequences (not shown) shows that channel 8 performs better in identifying the upper level PV and its strength, than do the difference channels, 7 minus 5. This fact is evident for example in cases 2 and 6: In case 2 (Israel), a warm A8 BT of $221 \mathrm{~K}$ can be found near the zonally elongated PV region with core values greater than 6 PVU, over the eastern Mediterranean Sea (Figure 7c). In contrast, no particular counterpart is observed in A7m5 (Figure 7d). Case 6 also 
(a)

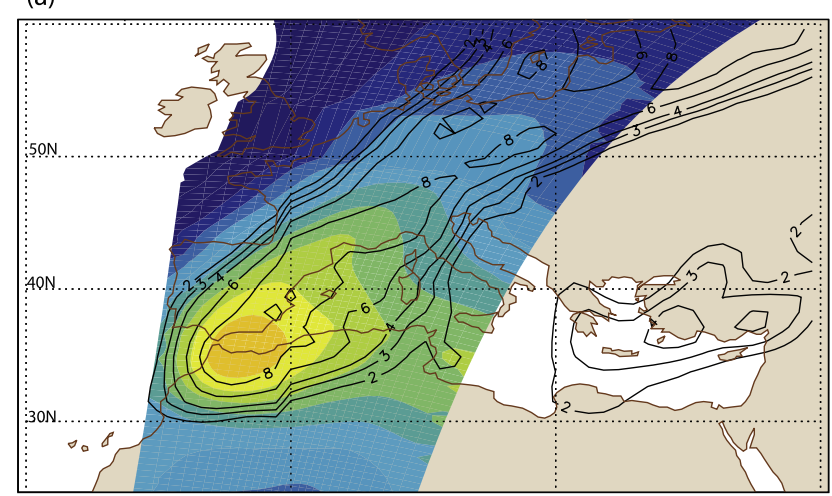

(c)

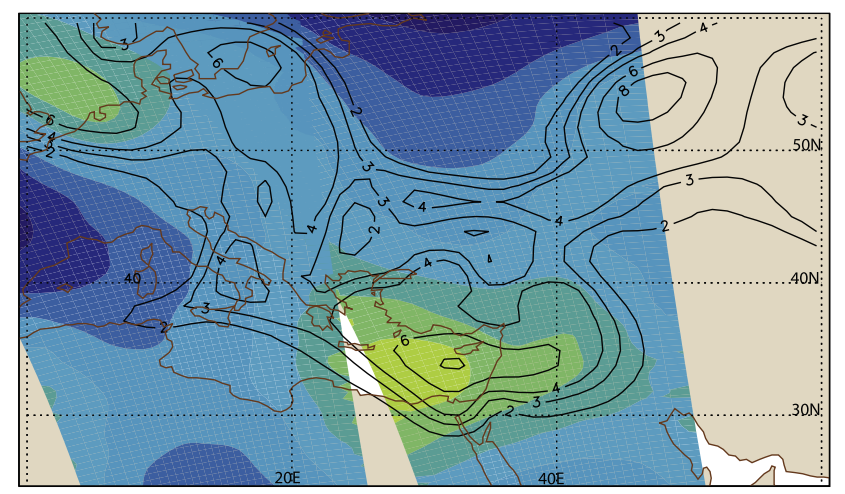

(e)
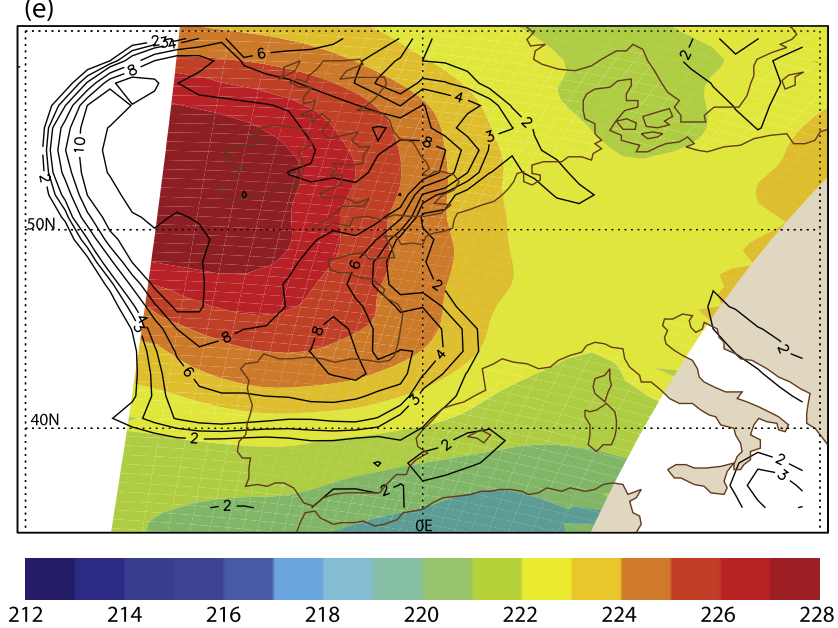

(b)

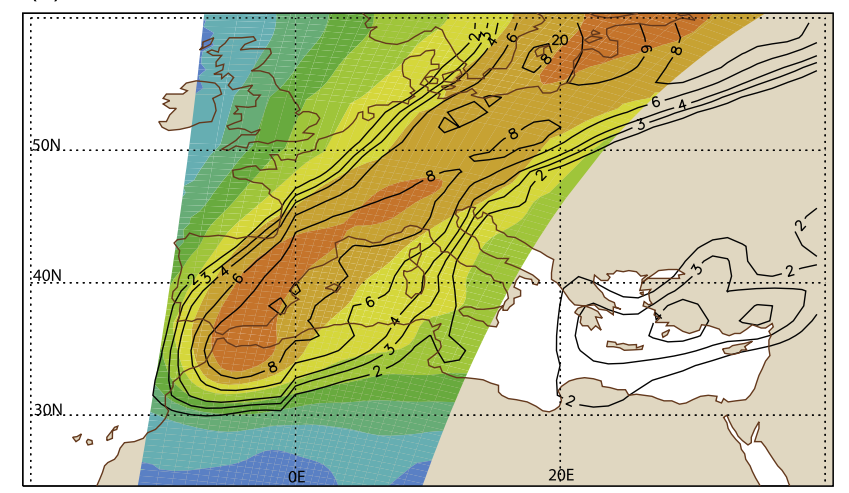

(d)
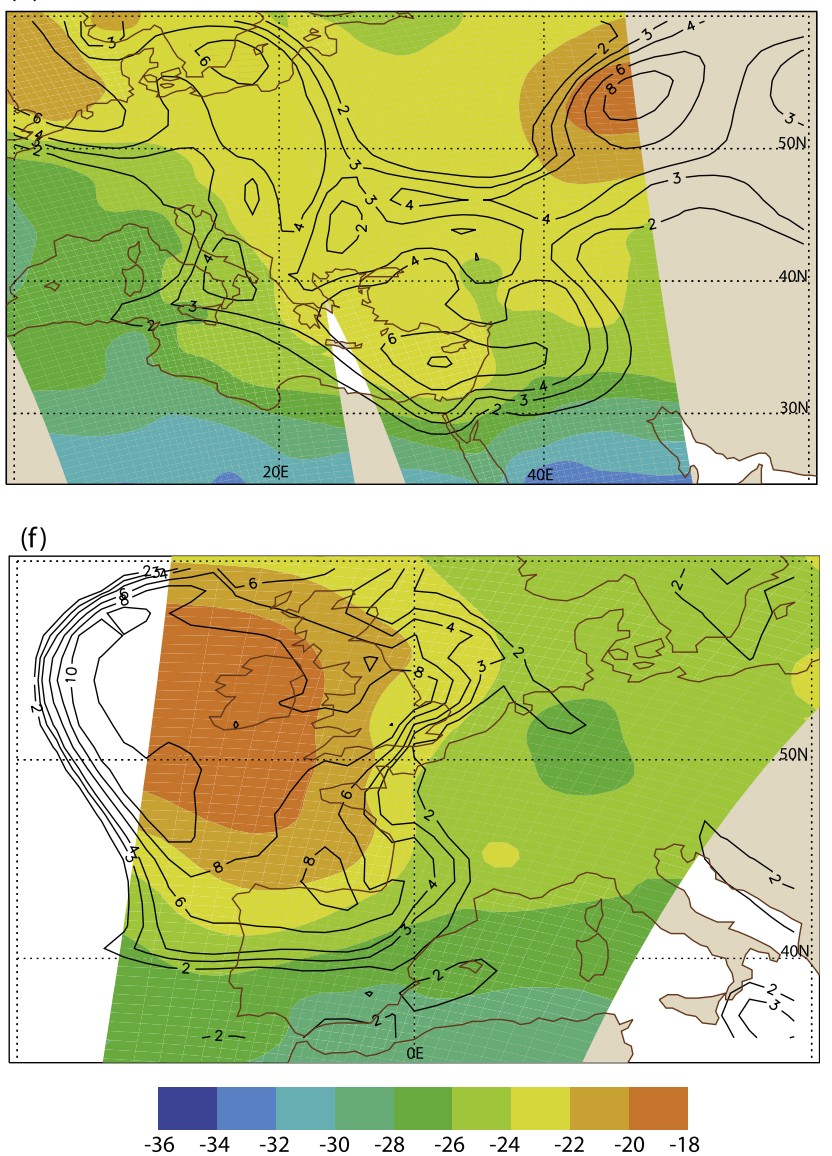

Figure 7. Limb-corrected AMSU-A channel 8 (left) and AMSU-A channel 7 minus 5 (right), for (a), (b) 01 UTC 10 November 2001, (c), (d) 9-11 UTC 4 December 2001, (e), (f) 02 UTC 9 September 2002, (g), (h) 11 UTC 5 December 2002, (h), (i) 02 UTC 2 December 2003, (j), (k) 02 UTC 8 September 2005. Thick contours are PV at $250 \mathrm{hPa}(2,3,4,6,8,10 \mathrm{PVU})$.

demonstrates a salient result: a cut-off low with core PV exceeding 6 PVU appears in the A8 BT as a warm core of $223 \mathrm{~K}$ (Figure $7 \mathrm{k}$ ), comparable with the A8 BT for case 1 (Figure 7a), but in A7m5 there is a dramatic change, with a BT value of $-24 \mathrm{~K}$ in case 6 (Figure 71 ) and $-20 \mathrm{~K}$ in case 1 (Figure $7 \mathrm{~b}$ ). Channel 8 is indeed more suitable to detect upper level features independent of the extent of their vertical penetration. A7m5 BTs are in good agreement with potential temperature on the 2 PVU surface (not shown), thus providing additional information as to the depth of the intrusion. Table 2 summarizes qualitatively the general findings regarding the shape, intensity of $\mathrm{PV}$ at $250 \mathrm{hPa}$ and corresponding A8 and A7m5 BT signals.

[24] A question that remains open is what is the most suitable threshold of BT that captures PV greater than 2PVU at $250 \mathrm{hPa}$. The determination of such a threshold is desired to objectively discriminate areas of southward mass intrusions that have potential to produce severe weather in the Mediterranean. A8 BT larger than $221 \mathrm{~K}$ roughly coincides with regions where $\mathrm{PV}$ is larger than 4 PVU. However, when the stratospheric intrusion has very large values of PV, the area where $\mathrm{A} 8 \mathrm{BT} \geq 221 \mathrm{~K}$ may cover a broader region than 
(g)

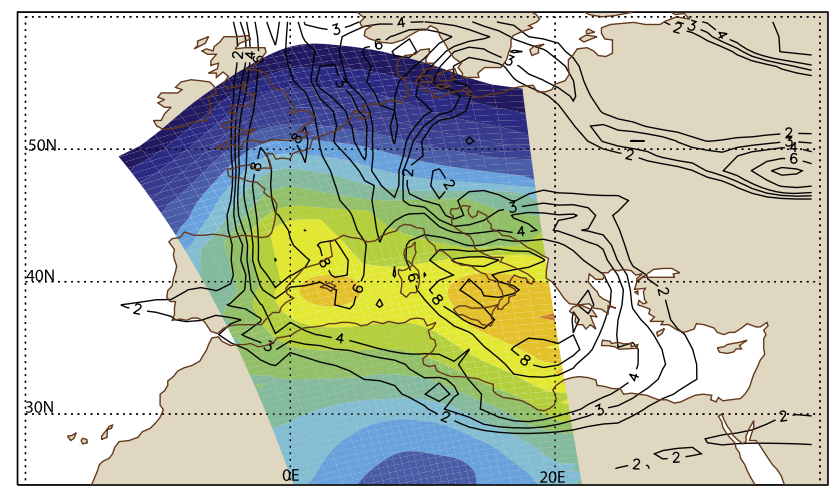

(i)

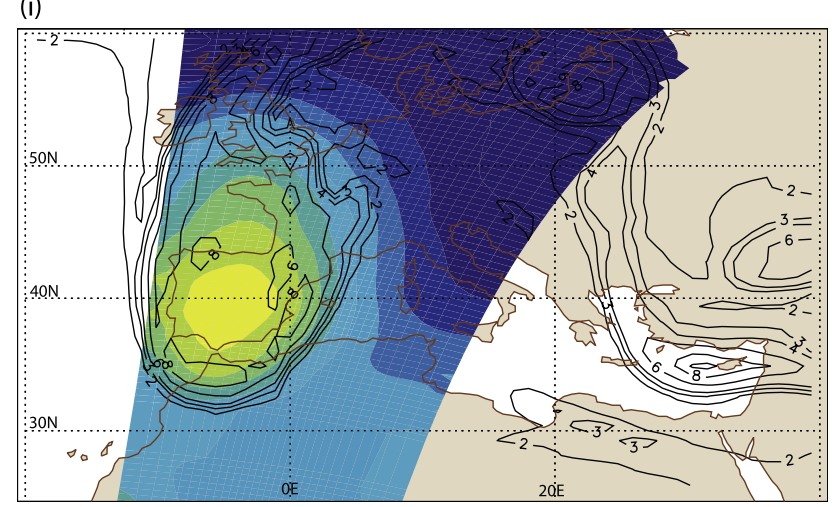

(k)
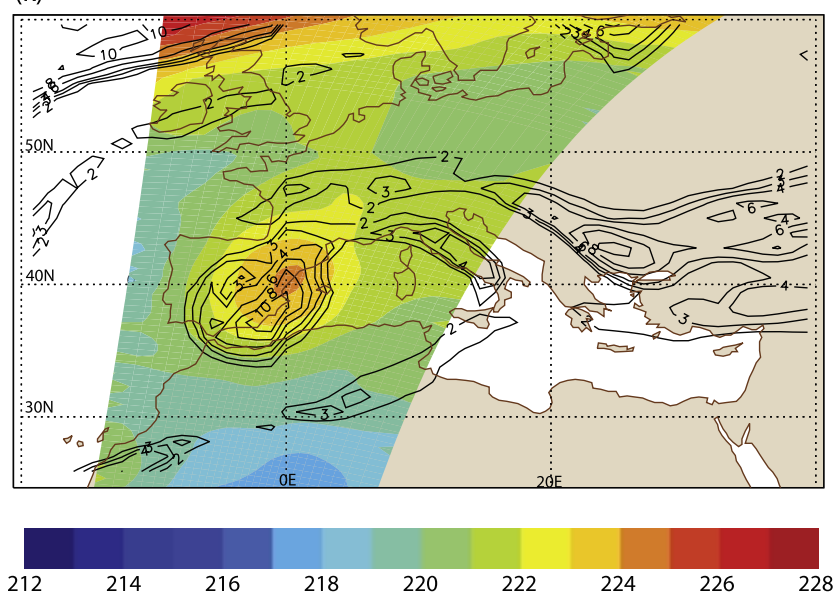

(h)
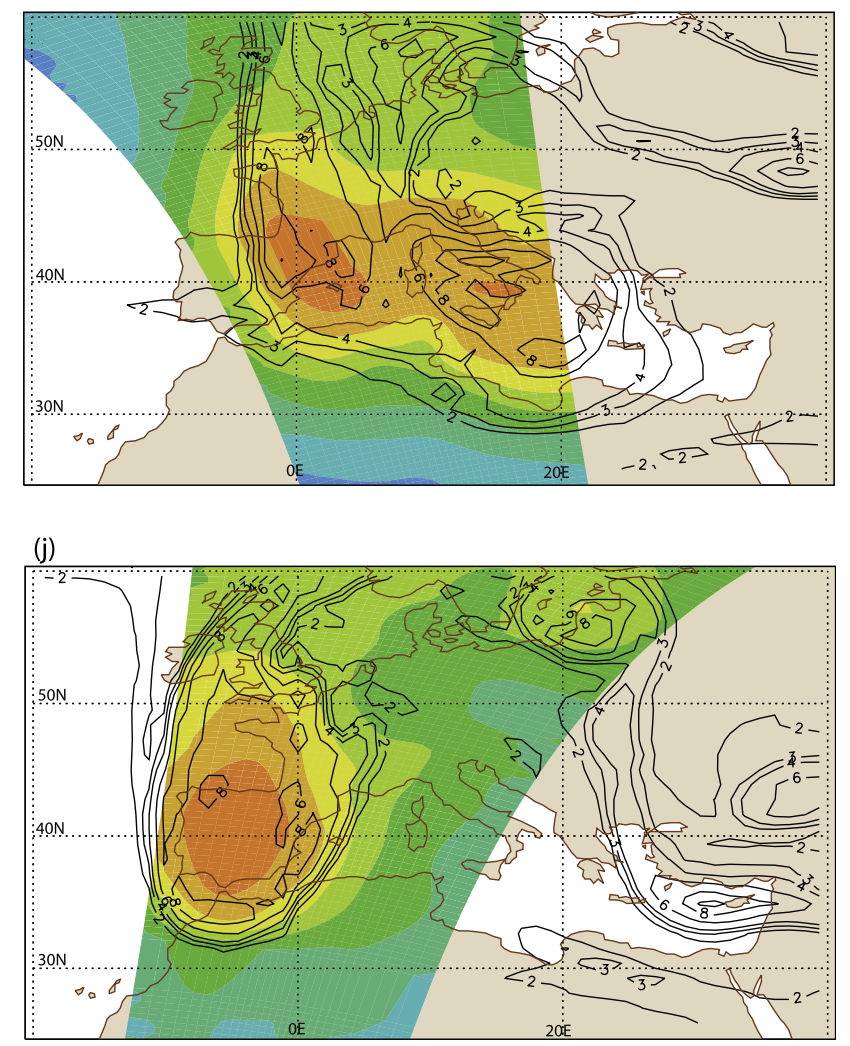

(I)
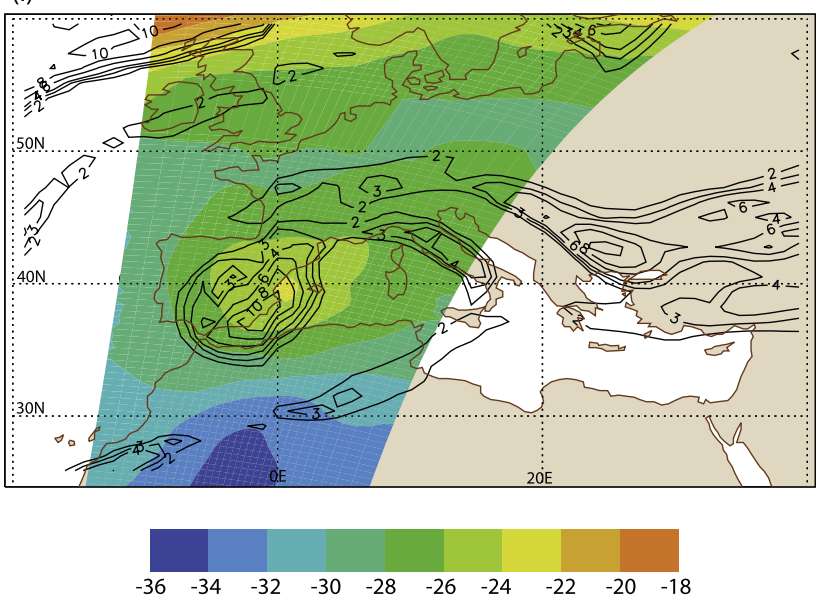

Figure 7. (continued)

the intrusion itself. This effect is more pronounced the larger the PV values. One such example is seen for case 3 , in Figure 7e: A8 BT $\geq 223 \mathrm{~K}$ delineates the area of intrusion, while the area covered by $\mathrm{A} 8 \mathrm{BT} \geq 221 \mathrm{~K}$ encompasses but does not define the PV trough. This suggests that the threshold of A8 BT $\geq 221 \mathrm{~K}$ can be taken as a "necessary" condition to detect significant PV anomalies, but further analysis is still needed to determine an absolute threshold.

Table 2. Characteristics of $\mathrm{PV}$ at $250 \mathrm{hPa}$ and Observed $\mathrm{A} 8$ and $\mathrm{A} 7 \mathrm{~m} 5 \mathrm{BTs}^{\mathrm{a}}$

\begin{tabular}{|c|c|c|c|c|}
\hline Case & Shape & $\operatorname{Max}(\mathrm{PV})$ & A8 & $\mathrm{A} 7 \mathrm{~m} 5$ \\
\hline Algiers (01 UTC 10/Nov/2001) & NE-SW elongated & 8 & $\sim 223$ & $<-18$ \\
\hline Cyprus (12 UTC 4/Dec/2001) & nearly zonally elongated & 6 & $\sim 221$ & $<-22$ \\
\hline Nîmes-Marseille (02 UTC 9/Sep/2002) & amorphous & $10(8)$ & $\gg 224$ & $<-18$ \\
\hline Antalya (11 UTC 5/Dec/2002) & ellipsoid (E) & $10(6)$ & $\sim 223$ & $<-18$ \\
\hline Rhône-Herault (02 UTC 2/Dec/2003) & N-S elongated & $6(4)$ & $\sim 222$ & $<-18$ \\
\hline Herault-Nîmes (03 UTC 6/Sep/2005) & "circular" & $10(8)$ & $>224$ & $<-22$ \\
\hline
\end{tabular}

${ }^{a}$ Values in brackets in $\max (\mathrm{PV})$ column indicate PV that is substantially larger in area than the maximum PV presented. PV in units of PVU, and BTs in K. 
One alternative approach to seek for the BT threshold would be to simulate A8 BTs from reanalysis fields and relate the results with the observed PV fields. Such approach was not taken here as it would require a great number of simulations to derive a statistically significant threshold.

\section{Detection of Precipitation Using AMSU-B 4.1. Methodology}

[25] We focus on AMSU-B channels 3 to 5 data for detection of precipitating systems. Greenwald and Christopher [2002] found that cold precipitating clouds causes an average depression of $7 \mathrm{~K}$ relative to the background temperature in AMSU-B channel 3 due to scattering of icy particles, resulting in a BT threshold of $235 \mathrm{~K}$ (for nadir measurements). This value was subsequently used by Hong et al. [2005] to detect precipitating systems in the tropical region. They also suggested a further criterion to identify deep convective and overshooting clouds, based on Doppler and Millimeter-wave Imaging Radiometer data, and simulation of BTs using a global cumulus ensemble cloud model data. The criterion proposed is that deep convective clouds satisfy simultaneously the condition B3m4 (i.e., the difference between channels 3 and 4 of AMSU-B), B3m5 and $\mathrm{B} 4 \mathrm{~m} 5$ greater or equal to zero. Because the channels further away from the center at $183.3 \mathrm{GHz}$ can probe deeper into the cloud, they are subject to greater scattering from the middle or low layers of the deep convective clouds. They showed that the above criterion, which we will refer hereafter as Deep Convection Threshold (DCT), provides a robust screening of strongly precipitating systems in the tropical region. However, in our study we are interested both in convective and non-convective precipitating systems, and tropical DCT criterion alone may leave out areas with less strong precipitation that are notwithstanding of interest when forming a climatology of precipitating systems. Therefore we seek for two thresholds in channels 3 to 5: One that is able to identify precipitating systems in general, and another that will indicate areas with deep convective clouds.

[26] The proposed rationale to determine a suitable cutoff threshold to identify precipitating systems (in general) is as follow: first, AMSU-B BTs are re-sampled to a regular grid $\left(0.25^{\circ}\right.$ lat $\left.\times 0.25^{\circ} \mathrm{lon}\right)$ coincident with $\mathrm{TRMM}$ data mesh, then differences between channels 3, 4, and 5 are taken. Second, we formed a histogram of B4m5, B3m4, and $\mathrm{B} 3 \mathrm{~m} 5 \mathrm{BTs}$ in bins of $1 \mathrm{~K}$ for the two first differences and $2 \mathrm{~K}$ for the latter (due to a larger BT distribution), corresponding to a "hit" relative to TRMM accumulated precipitation greater or equal $10 \mathrm{~mm}$ in $3 \mathrm{~h}$. The value of $10 \mathrm{~mm} / 3 \mathrm{~h}$ was arbitrarily chosen to represent moderate rainfall. Then, the same is done for each grid point where accumulated precipitation is found to be zero, representing the "false positives". Finally, a cumulative curve for each category is plotted, and the point of interception of these two curves shows the BT in which the "hits" overcome the "false positives", representing an estimate of a suitable BT that is able to detect precipitation while containing false positives. This rationale is obviously imperfect, in one hand due to the subjectivity of the threshold, and on the other, as already stated earlier, because 3 -h accumulated precipitation (TRMM) is compared to an instantaneous observation
(AMSU-B) that falls within any moment within the fixed 3 - $\mathrm{h}$ span and could be at a moment when the precipitation is not the strongest. Nevertheless, we argue that the above rationale yields a reasonable estimate of the BT that represents statistically a moderately precipitating system.

[27] The second threshold we seek for is to discriminate convective systems. In order to examine whether the tropical DCT is applicable to detect heavily precipitating systems in the Mediterranean, we performed a search of all grid points where DCT condition is satisfied and compared to the TRMM accumulated precipitation in $3 \mathrm{~h}$ at the same grid points in order to obtain an estimate of the precipitation levels that this condition can detect.

\subsection{Results}

[28] We used three sets of satellite images to search for a threshold based on AMSU channels 3 to 5 to isolate precipitating systems yielding accumulated precipitation above $10 \mathrm{~mm} / 3 \mathrm{~h}$ :

[29] (i) 20 overpasses covering case studies listed in section 1;

[30] (ii) 31 overpasses of NOAA-16 and 35 passes of NOAA-17 for the events over France only (6-10 September 2002; 1-3 December 2003; 4-9 September 2005);

[31] (iii) 150 overpasses in November 2001 (NOAA-16), that fell within the area of $30^{\circ}-60^{\circ} \mathrm{N}, 20^{\circ} \mathrm{W}-45^{\circ} \mathrm{E}$.

[32] Within each subset, overpasses are selected such that the area of comparison between TRMM and AMSU fall within the following domains: In (i) the area of comparison is variable and centered near the place where the heavy rainfall event occurred. In (ii), the domain of search is $\left[30-50^{\circ} \mathrm{N}, 20^{\circ} \mathrm{W}-20^{\circ} \mathrm{E}\right]$. In (iii) two areas are considered, $\left[34-42^{\circ} \mathrm{N}, 10^{\circ} \mathrm{W}-5^{\circ} \mathrm{E}\right]$ for the West Mediterranean, and $\left[30-39^{\circ} \mathrm{N}, 22.5-35^{\circ} \mathrm{E}\right]$ for the East Mediterranean. In the latter, we selected the search areas based on maps of mean snow depth and surface pressure for November 2001, so that regions that include surface snow cover were not included (for example, the Alps, the Carpathians mountains in Romania and the mountainous coast of Croatia along the eastern border of the Adriatic Sea). Results are summarized in Table 3.

[33] The average values of $\mathrm{B} 3 \mathrm{~m} 4, \mathrm{~B} 3 \mathrm{~m} 5$ and $\mathrm{B} 4 \mathrm{~m} 5$ obtained for cases (i)-(iii) are, respectively, $-5.9 \pm 0.8 \mathrm{~K}$, $-8.4 \pm 1.0 \mathrm{~K}$, and $-1.8 \pm 1.0 \mathrm{~K}$. The smallest standard deviation is of $\mathrm{B} 3 \mathrm{~m} 4$, however, $\mathrm{B} 3 \mathrm{~m} 5$ has the smallest standard deviation relative to its mean (less than $12 \%$, compared to around $14 \%$ for $\mathrm{B} 3 \mathrm{~m} 4$ and $56 \%$ for $\mathrm{B} 4 \mathrm{~m} 5$ ), indicating that this combination is the most robust, and in a statistical sense a value of $\mathrm{B} 3 \mathrm{~m} 5 \geq-8 \mathrm{~K}$ will have more chance of detecting precipitation than yielding a false positive (once snow-covered areas are discarded). Potential differences in thresholds for NOAA-16 and NOAA-17 were explored comparing approximately the same number of passes for each satellite, for case studies 3, 5, and 6. Results shows that the difference is of nearly $1.5 \mathrm{~K}$ for $\mathrm{B} 3 \mathrm{~m} 4$, less than $1 \mathrm{~K}$ for $\mathrm{B} 4 \mathrm{~m} 5$, and of $2.5 \mathrm{~K}$ for $\mathrm{B} 3 \mathrm{~m} 5$, with colder threshold for NOAA-17. Therefore whichever threshold chosen may yield a slight underestimation of precipitating systems in NOAA-17.

[34] The validity of tropical DCT for the Mediterranean region was examined using two nearly independent data sets: one for the climatology of November 2001 (150 
Table 3. Value of BT Differences B3m4, B4m5, and B3m5, in K, Where the Number of Hits Exceeds the Number of False Positives Relative to TRMM 3B42 3-h Accumulated Precipitation Above $10 \mathrm{~mm}$

\begin{tabular}{lcccc}
\hline Case (num. passes) & {$[$ Lat, Lon] } & B3m4 & B4m5 & B3m5 \\
\hline Case studies (20) & variable & -5.3 & -2.2 & -8.3 \\
West Med (150) & {$\left[34^{\circ}-42^{\circ} \mathrm{N},-10^{\circ}-5^{\circ} \mathrm{E}\right]$} & -5.3 & -1.3 & -8.0 \\
East Med (150) & {$\left[30^{\circ}-39^{\circ} \mathrm{N}, 22.5^{\circ}-35^{\circ} \mathrm{E}\right]$} & -6.6 & -0.5 & -8.0 \\
NOAA-16 (31) & {$\left[30^{\circ}-50^{\circ} \mathrm{N},-20^{\circ}-20^{\circ} \mathrm{E}\right]$} & -5.3 & -2.3 & -7.5 \\
NOAA-17 (35) & {$\left[30^{\circ}-50^{\circ} \mathrm{N},-20^{\circ}-20^{\circ} \mathrm{E}\right]$} & -6.8 & -3.0 & -1.0 \\
$\bar{x}$ & & -5.9 & -1.8 & -8.4 \\
Std. dev. & - & 0.8 & 1.0 & 1.0 \\
[Std.dev.] $/ \bar{x}^{*} 100(\%)$ & & 14 & 55 & 12 \\
\hline
\end{tabular}

passes), for the areas shown in Table 3 for west and east Mediterranean, and the other, 20 passes for the 6 case studies. Figure 8 shows the cumulative distribution of values of TRMM accumulated precipitation for grid points where DCT was found. These results show that between $70-80 \%$ of the cases whenever the DCT criterion is reached there is accumulated precipitation. In nearly $50 \%$ of the cases there is 3-h accumulated precipitation above $20 \mathrm{~mm}$. Because of the aforementioned differences in the nature of the accumulated precipitation as compared to instantaneous observations, it is not possible to firmly determine the validity of DCT for the Mediterranean region. Despite these limitations, the above results are encouraging for its application in the Mediterranean.

[35] Qiu et al. [2005] introduced parameters to characterize convection also using AMSU-B channels moisture channels (3 to 5). They defined three convective indexes: CI1 (indicator of weak convection or stratiform rain) when $\mathrm{B} 4 \mathrm{~m} 5>-2 \mathrm{~K}, \mathrm{~B} 4 \mathrm{~m} 5>\mathrm{B} 3 \mathrm{~m} 5$, and $\mathrm{B} 4 \mathrm{~m} 5>\mathrm{B} 3 \mathrm{~m} 4$; $\mathrm{CI} 2$ (indicator of moderate convection) when both DCT and $\mathrm{B} 4 \mathrm{~m} 5>\mathrm{B} 3 \mathrm{~m} 4$ are satisfied; and CI3 (indicator of strong convection) when both DCT and $\mathrm{B} 3 \mathrm{~m} 5>\mathrm{B} 3 \mathrm{~m} 4>\mathrm{B} 4 \mathrm{~m} 5$ are satisfied. CI3 is analogous to the condition of convective overshooting of Hong et al. [2005] for the tropical region. Based on the 150 overpasses in November 2001 and 20 overpasses of case studies, we found that the condition CI1 is attained more frequently than the threshold of $\mathrm{B} 3 \mathrm{~m} 5 \geq$

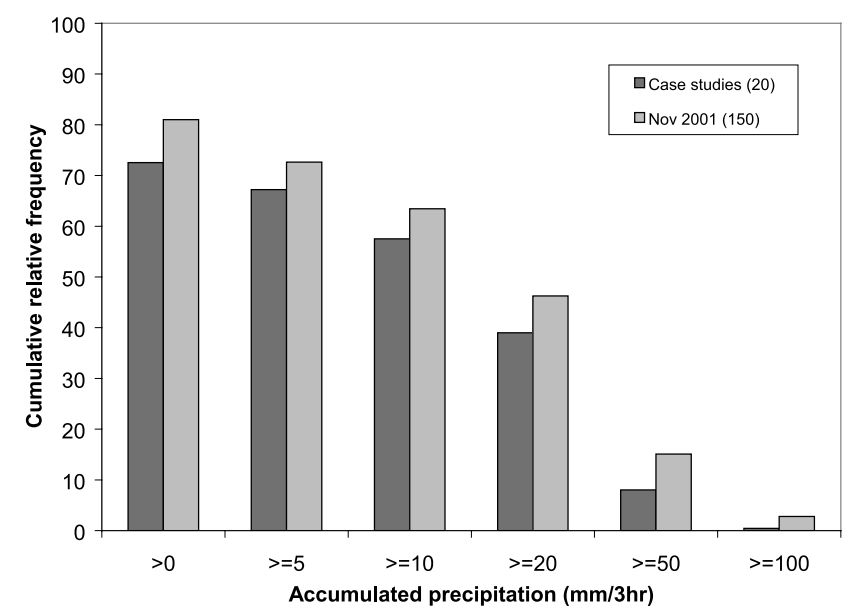

Figure 8. Cumulative relative frequency of accumulated precipitation given by TRMM for grid points where DCT was found, for 20 passes of case studies, and 150 passes in November 2001. Total number of grid points for case studies was 885, and 1001 for November 2001.
$-8 \mathrm{~K}$ but yields more false alarms compared to TRMM data (39\% for $\mathrm{B} 3 \mathrm{~m} 5 \geq-8 \mathrm{~K}, 53 \%$ for CI1) and lesser matches with TRMM data $\geq 10 \mathrm{~mm} / 3 \mathrm{~h}(39 \%$ for $\mathrm{B} 3 \mathrm{~m} 5 \geq-8 \mathrm{~K}$, $27 \%$ for $\mathrm{CI} 1)$. In $73 \%$ of the cases where $\mathrm{B} 3 \mathrm{~m} 5 \geq-8 \mathrm{~K}$ was found CI1 condition was satisfied, $35 \%$ of which there was TRMM data $\geq 10 \mathrm{~mm} / 3 \mathrm{~h}$. This indicates that additional inclusion of conditions to meet condition CI1 did not improve the matches with respect to TRMM data. Results are summarized in Table 4. A similar result was found for DCT condition compared with CI2 and CI3. When DCT is found, about $77 \%$ of the total number of grid points have TRMM data $>0$ (23\% false positives). This percentage was unchanged when $\mathrm{CI} 2$ was satisfied. However, there was a slight decrease in the percentage of matches with TRMM

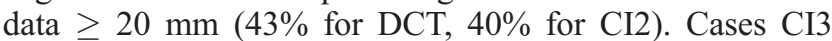
comprised only $19 \%$ of DCT grid points. We conclude that our method is either more suitable or equivalent to the indices proposed by Qiu et al. [2005] for rain detection in the Mediterranean, based on comparison with TRMM data.

[36] To further examine the validity of the thresholds for rain detection (i.e., $\mathrm{B} 3 \mathrm{~m} 5 \geq-8 \mathrm{~K}$ for precipitating systems and DCT for convective clouds), an example of their application and comparison with independent radar and ground measurements are shown for case 3. On 8-9 September 2002, a mesoscale convective system passed over Gard Region (south France) causing strong rainfall and flash floods. A synoptic and hydrological study of this storm is detailed in Delrieu et al. [2005]. Southerly flow of warm and moist air at low levels was induced by a well defined upper level PV disturbance (e.g., see Figures 6e and 6f). The particular topographical disposition of the area affected Pyrenees in the west, Alps in the east and the Massif Central in central France - promoted enhanced low-level convergence of this moist air and release of convective instability. The strong rainfall yielded accumulated precipitation of $690 \mathrm{~mm} / 24 \mathrm{~h}$ at some locations. Figure $9 \mathrm{a}$ and $9 \mathrm{~b}$ show a comparison between $\mathrm{B} 3 \mathrm{~m} 5 \geq-8 \mathrm{~K}$ and DCT with $\mathrm{SQR}$ and

Table 4. Absolute Number of Gridpoints in Which B3m5 $\geq-8 \mathrm{~K}$ and CI1 are Satisfied and Comparison With TRMM 3B42 3-hr Accumulated Precipitation, Based on 150 NOAA-16 Overpasses in November 2001 and 20 Overpasses in Case Studies

\begin{tabular}{lcc}
\hline \multicolumn{1}{c}{ Condition Satisfied } & B3m5 $\geq-8 \mathrm{~K}$ & CI1 \\
\hline Total number of gridpoints & 9264 & 10,848 \\
B3m5 $\geq-8 \mathrm{~K}$ & $(9264)$ & 6800 \\
CI1 & 6800 & $(10,848)$ \\
TRMM $\geq 10 \mathrm{~mm}$ & 3610 & 2887 \\
CI1 + TRMM $\geq 10 \mathrm{~mm}$ & 2366 & - \\
TRMM $=0 \mathrm{~mm}$ & 3602 & 5719 \\
\hline
\end{tabular}



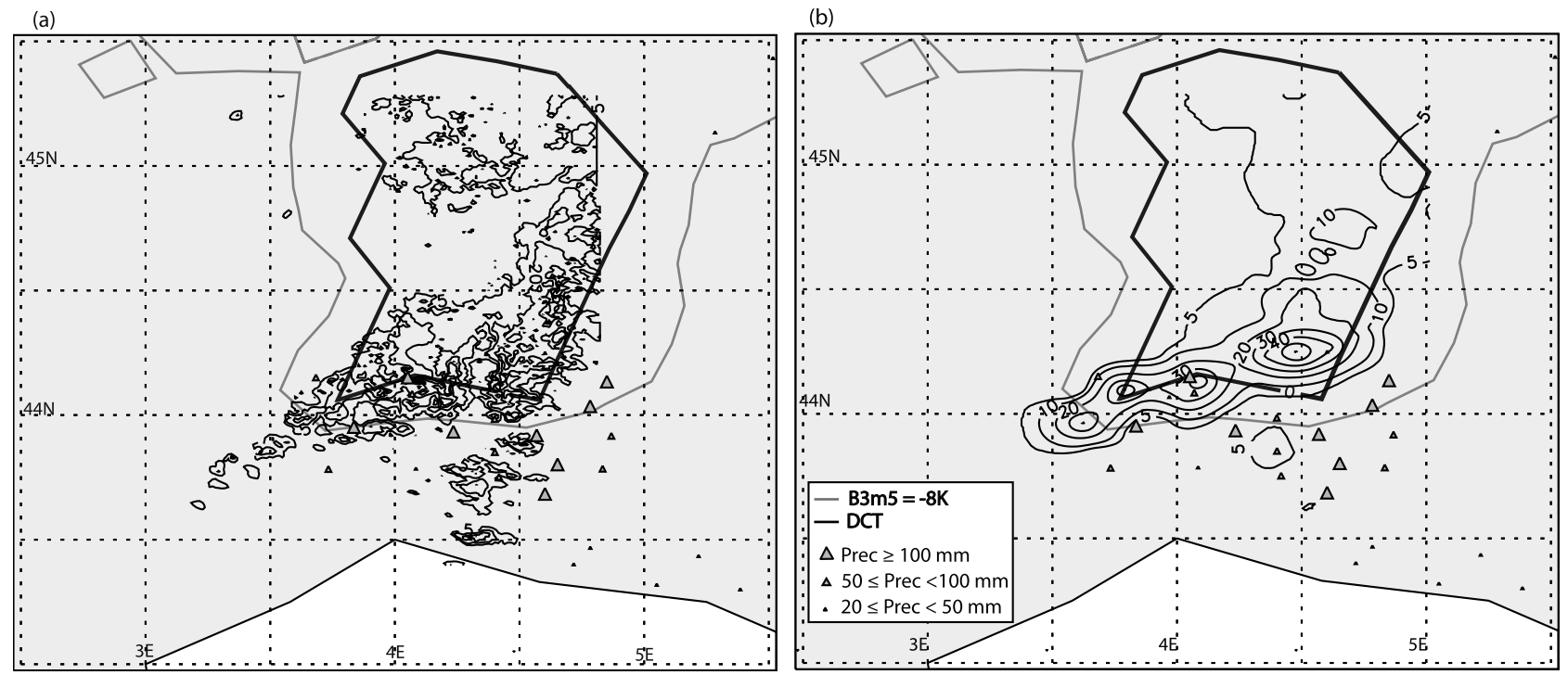

Figure 9. AMSU-B channel 3 minus 5 BT (-8K), DCT (thick dark), SQR accumulated rainfall data (triangles), and (a) radar derived precipitation intensity $(\mathrm{mm} / \mathrm{h}$ ) and (b) rain gauge network 1-h accumulated precipitation $(\mathrm{mm})$, from the Cévennes-Vivarais Mediterranean Hydrometeorological Observatory. SQR indicates accumulated rainfall between 05 UTC 08 September to 05 UTC 09 September 2002; position of triangle is the position of measuring station.

OHM-CV precipitation data. SQR data indicates $24 \mathrm{~h}$ accumulated rainfall from 05 UTC 8 September to 05 UTC 9 September 2002. OHM-CV radar-derived precipitation intensity is shown at 0230 UTC 9 September, and accumulated precipitation is over $1 \mathrm{~h}$ (i.e., between 02-03 UTC 9 September 2002). There is a quite good agreement between the area defined by $\mathrm{B} 3 \mathrm{~m} 5 \geq-8 \mathrm{~K}$ and DCT with the independent $\mathrm{SQR}$ and $\mathrm{OHM}-\mathrm{CV}$ data. $\mathrm{B} 3 \mathrm{~m} 5=-8 \mathrm{~K}$ and DCT define a region in which there is significant accumulated precipitation in the next hour (OHM-CV) and/or subsequent hours (SQR). However, a small area of large accumulated precipitation measured by radar and raingauges, between approximately $43.5^{\circ}$ and $44^{\circ} \mathrm{N}$, is seen outside this region. This apparent failure of AMSU-B to detect these areas can be explained by the different nature of these observations: while AMSU provides a near-instantaneous observation, the radar-derived and raingauge data provide an accumulated rainfall value. It could be that the precipitation accumulated in the "mismatch" area fell after the satellite passed. We stress once more that the aim in our methodology is not to provide rain rates but to detect areas of significant precipitation.

[37] An additional comparison with TRMM and ground data is shown in Figure 10 between 00 UTC 9 November and 01 UTC 11 November 2001 (extreme event in Algiers, see section 1). The overlap between B3m5 and DCT thresholds and TRMM accumulated precipitation clearly indicates that our thresholds detect precipitation not only over land but also over the Mediterranean Sea. Moreover there is a very good correspondence between areas where there is significant rainfall measured by ground stations and areas determined by our method. Another important point is that there is minimal cases of "false alarms". Because the AMSU-B measurements and ground stations are completely independent, the above results give us additional confidence that these thresholds are suitable for detecting moderate to strong rainfall.

\section{Two Rainfall Events}

[38] To further demonstrate the applicability of the thresholds found above, we depict here two heavy rainfall events through a series of AMSU observations, in which consecutive orbits are concatenated to form a single map: case 1, of Algiers (9 and 10 November 2001), and case 4, of Antalya, in the Mediterranean coast of Turkey (5 and 6 December 2002).

\subsection{Algiers, 9-10 November 2001}

[39] The dominant feature for this event was a deep, elongated and narrow PV intrusion with an axis in the NE-SW direction that evolved prior to the rapid cyclogenesis (e.g., Figures 6a and 7b). The coupling between this upper level system with warm surface air over the Mediterranean led to a rapid surface cyclogenesis and intense precipitation [Tripoli et al., 2005], while local orography had only a secondary role [Moore et al., 2005]. Heavy precipitation was recorded over the Moroccan and Algerian coastal areas, with the most severe precipitation reaching west of the city of Algiers, with $110 \mathrm{~mm}$ accumulated between 06 and 09 UTC 10 November. By 06 UTC 11 November the surface cyclone reached Balears, where it caused extensive damage. Additional synoptic details can be found in, e.g., Tripoli et al. [2005] and Argence et al. [2006]. The time evolution of the upper level trough and the relative position of the associated precipitation is depicted in Figure 11, which shows NOAA-16 A8, B3m5 $\geq-8 \mathrm{~K}$ and DCT for the period of 8-11 November 2001.

[40] Between 08 - 12 UTC 8 November 2001 a small trough-like feature can be seen from AMSU-A over NE Europe, on the Atlantic Ocean and north of France 

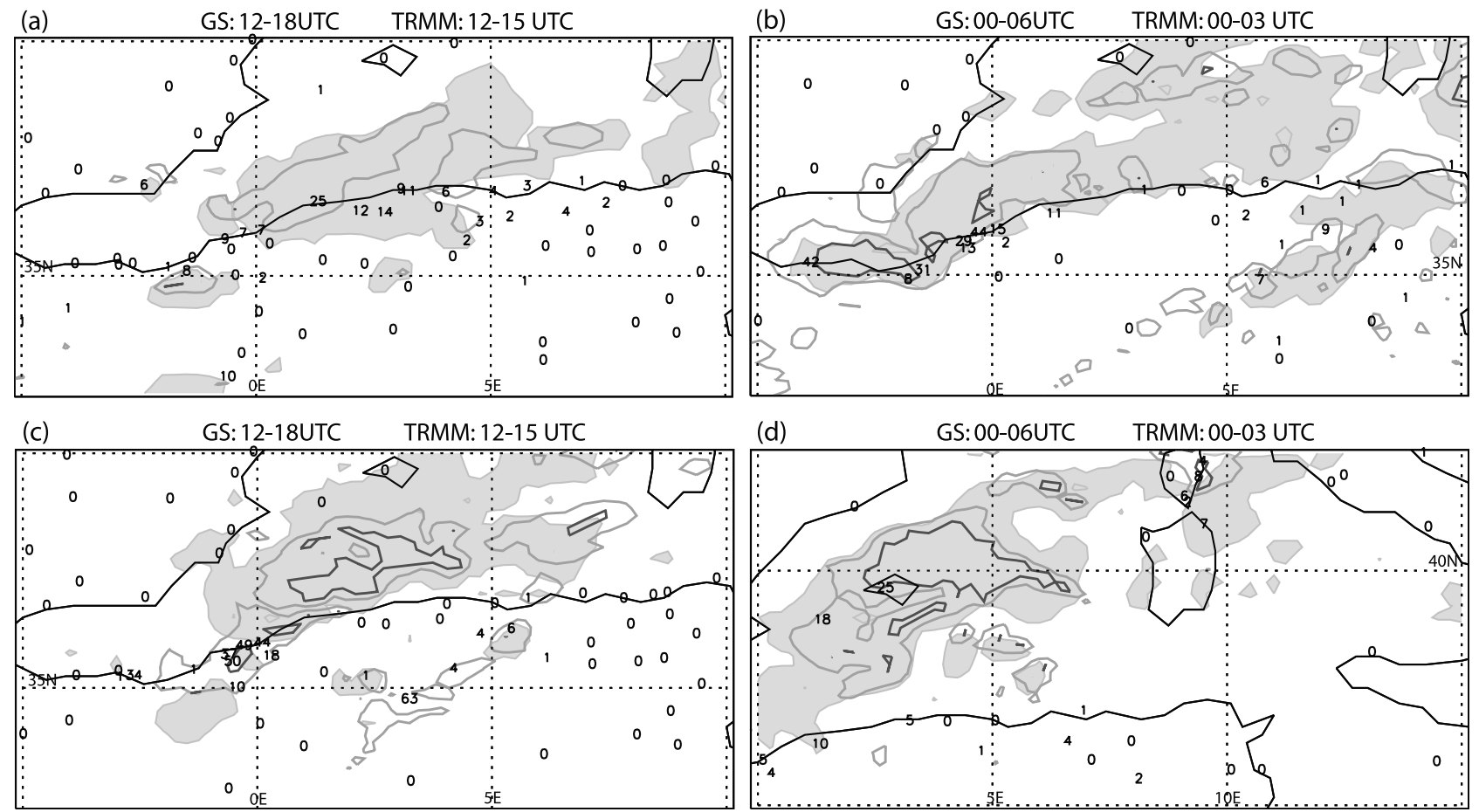

Figure 10. AMSU-B channel 3 minus 5 BT (-8K, gray contour), DCT (dark gray contour), ground station (GS) accumulated rainfall over $6 \mathrm{~h}$ (in $\mathrm{mm}$; span indicated on top of panel), TRMM accumulated rainfall larger than $10 \mathrm{~mm}$ in $3 \mathrm{~h}$ (shaded, hour span indicated on top of panel), for (a) 12 UTC 9 November 2001, (b) 01 UTC 10 November 2001, (c) 12 UTC 10 November 2001, and (d) 01 UTC 11 November 2001.

(Figure 11a). No convective systems associated with this feature are observed at this time. By the night of 8 November and early hours of 9 November 2001 (Figure 11b) the upper level feature is located over France and a band of non-convective precipitation is observed at its southern edge, over the Atlantic and the Pyrenees. A semi-stationary upper level feature is observed over south Tunisia and NW of Libya, with no precipitation associated. The sequence of Figures 11c-11e shows that as the upper level disturbance intensifies and moves southwards, a broad area of precipitation and convective clouds are observed downstream (Figure 11c) or coincident (Figures 11d and 11e) with the area of large BT. Between 22 UTC 10 November and 03 UTC 11 November the upper level disturbance "splits" to a cut-off-like warm core centered on Algeria. A very large convective area is observed at this time over the Balearic Islands (Figure 11f), where it caused severe storms and floods. As the upper level disturbance weakens, the convective areas diminishes. This example shows that A8, $\mathrm{B} 3 \mathrm{~m} 5$ and the DCT are able to depict the essential features of this event. Another example is shown for the severe weather event in Antalya.

\subsection{Antalya, 5-6 December 2002}

[41] The heavy rainfall event that occurred in Antalya (southwestern Mediterranean coast of Turkey) produced more than $230 \mathrm{~mm} / 24 \mathrm{~h}$ and caused floods in this area. The storm was a product of the interaction of a north-south oriented cold front with a mid-tropospheric trough and associated cut-off low west of the surface system and an upper-level jet, which extended zonally across the south- eastern Mediterranean [Kotroni et al., 2006]. The maximum precipitation in Antalya occurred up to 18 UTC 5 December. At this time, the upper level trough axis had a cyclonic turn and the jet was positioned with its left exit region over south of Antalya which, combined with the effect of orography circling the region, favored ascending flow over this area. For a more detailed synoptic description, see, e.g., Kotroni et al. [2006].

[42] Figure 12 shows $\mathrm{A} 8, \mathrm{~B} 3 \mathrm{~m} 5 \geq-8 \mathrm{~K}$ and DCT for NOAA-16 satellite pictures composited for 4-6 December. Near 00 UTC 4 December, the upper level feature as depicted by A8 BT is seen to have a northwest-southeast orientation, with a core centered to the west of Sicily (Figure 12a). Precipitation occurs over the coast of Croatia, in association with the cold front over the Adriatic Sea. The upper level feature progresses slowly eastward, and strong precipitation is detected at the west coast of Greece (Figure 12b).

[43] On the 5th, the upper level disturbance takes a more zonally oriented configuration especially on its western side (Figure 12d). Precipitation is located within the area of A8 BT larger than $221 \mathrm{~K}$. At this point convective precipitation cells appear in the eastern side of the Balkan Peninsula, ahead of the warm A8 BT core. On the 6th (Figures 12e and 12f), the upper level disturbance over the eastern Mediterranean is much weaker, and another warm A8 BT core is observed over north of Algeria. A strong precipitating cell is observed over Antalya $\left(36.52^{\circ} \mathrm{N}, 30.45^{\circ} \mathrm{E}\right)$ and its vicinity between 22 UTC 5 December and 03 UTC 6 December, as well as in the Adriatic Sea and Western Mediterranean Sea. 
(a)

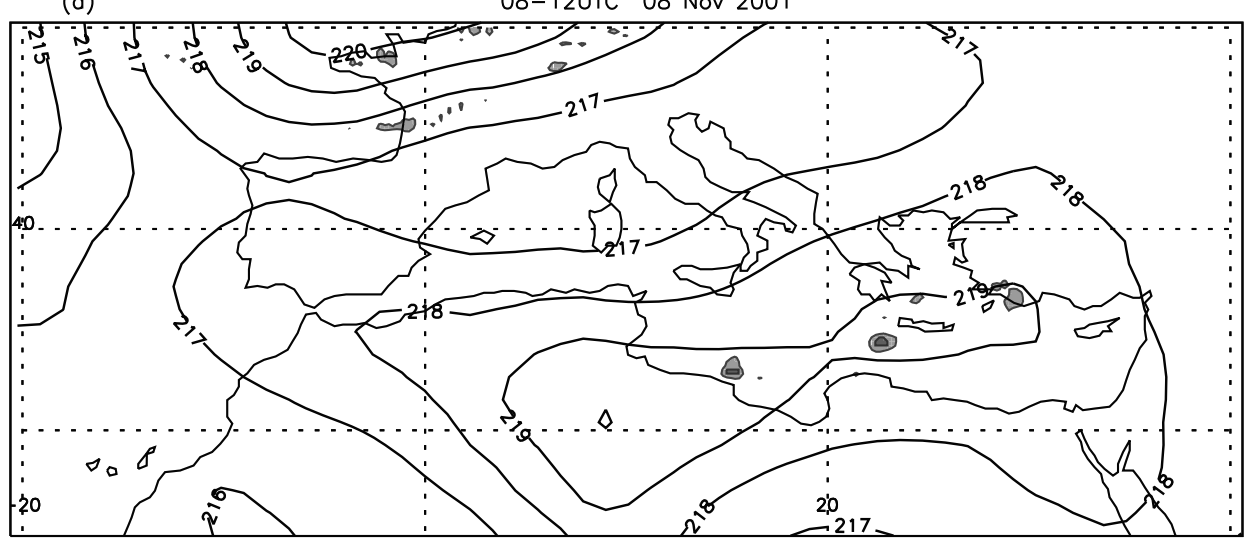

(b) 22-03UTC 09 Nov 2001
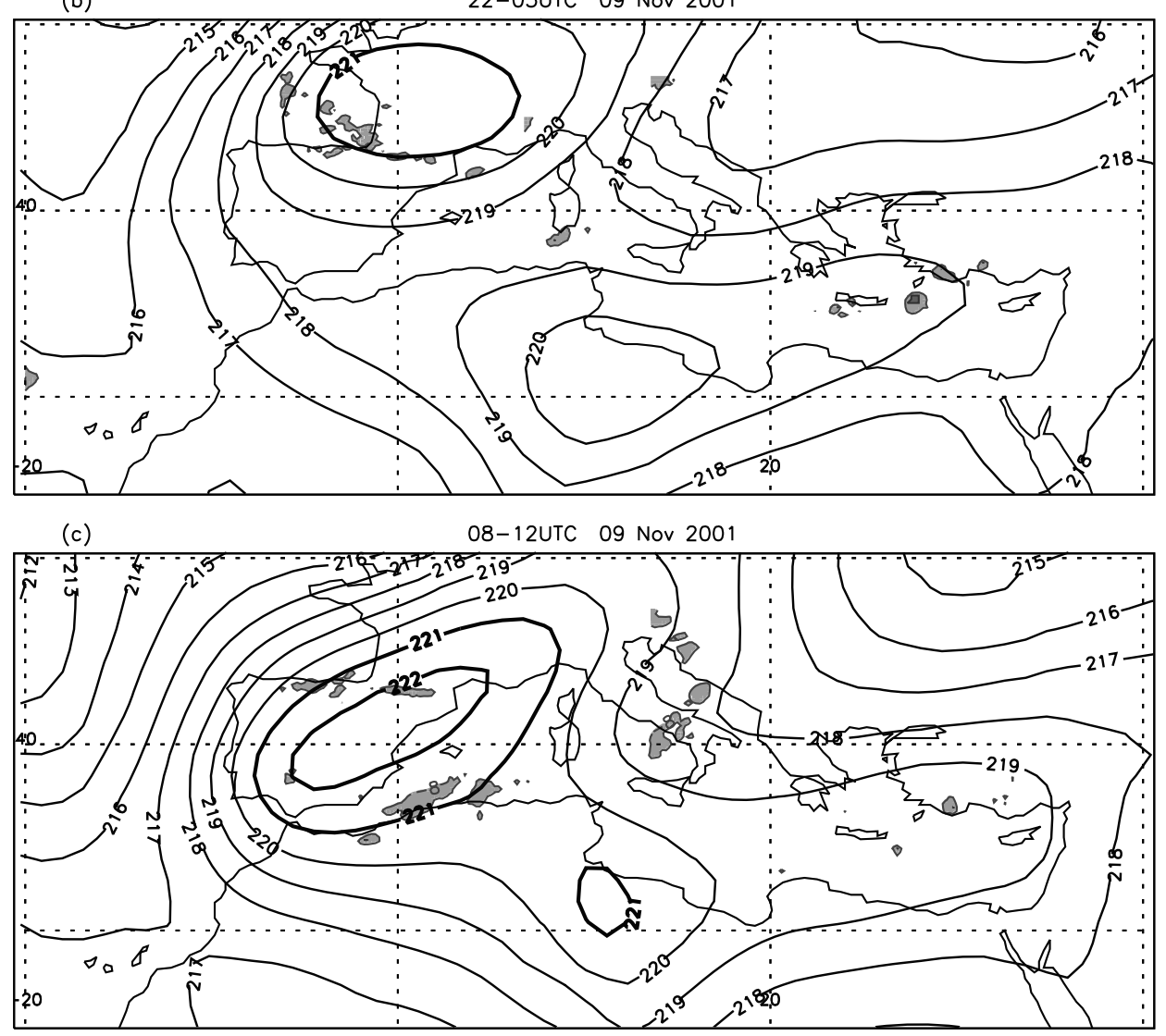

Figure 11. AMSU-A channel 8 (solid, thick dark for A8 BT $\geq 221 \mathrm{~K}$ ), B3m5 ( $\geq-8 \mathrm{~K}$, light gray shaded) and DCT (dark gray shaded) for (a), (c), (e), (g) ascending (08-13 UTC) and (b), (d), (f) descending (22-03 UTC),NOAA-16 passes, for 8-10 November 2001. A8 BT are interpolated from the original irregular grid to a regular grid of $1.125^{\circ}$ lat $\times 1.125^{\circ}$ lon, using a weight of $\left[1-(\mathrm{d} / \mathrm{df})^{2}\right]$, where $\mathrm{d}$ is the distance between the original (lat,lon) of satellite data to the regular grid point, and $\mathrm{df}$ is an arbitrary 'reference distance', set to be of $2.5^{\circ}$ (converted to $\mathrm{km}$ ).

Finally, later on this day, the precipitation has weakened over the Eastern Mediterranean, while other precipitating cells are found at the south of Italy, south and west of Sicily, and north of Algeria.

[44] As in the previous case, the thresholds found in this study are seen to diagnose the upper level condition and the heavily precipitating cell at 23 UTC 5 December (easternmost pass) over Antalya. Also, it is seen in both cases that an upper level feature is detected prior to the occurrence of intense precipitation. With the satellite data depiction shown here we have an indication that these precipitating systems are forced in large scale rather than locally driven.

\section{Summary and Conclusions}

[45] In this work we demonstrated the potential of both AMSU-A to detect upper level disturbances that are often precursors of severe weather systems in the Mediterranean 

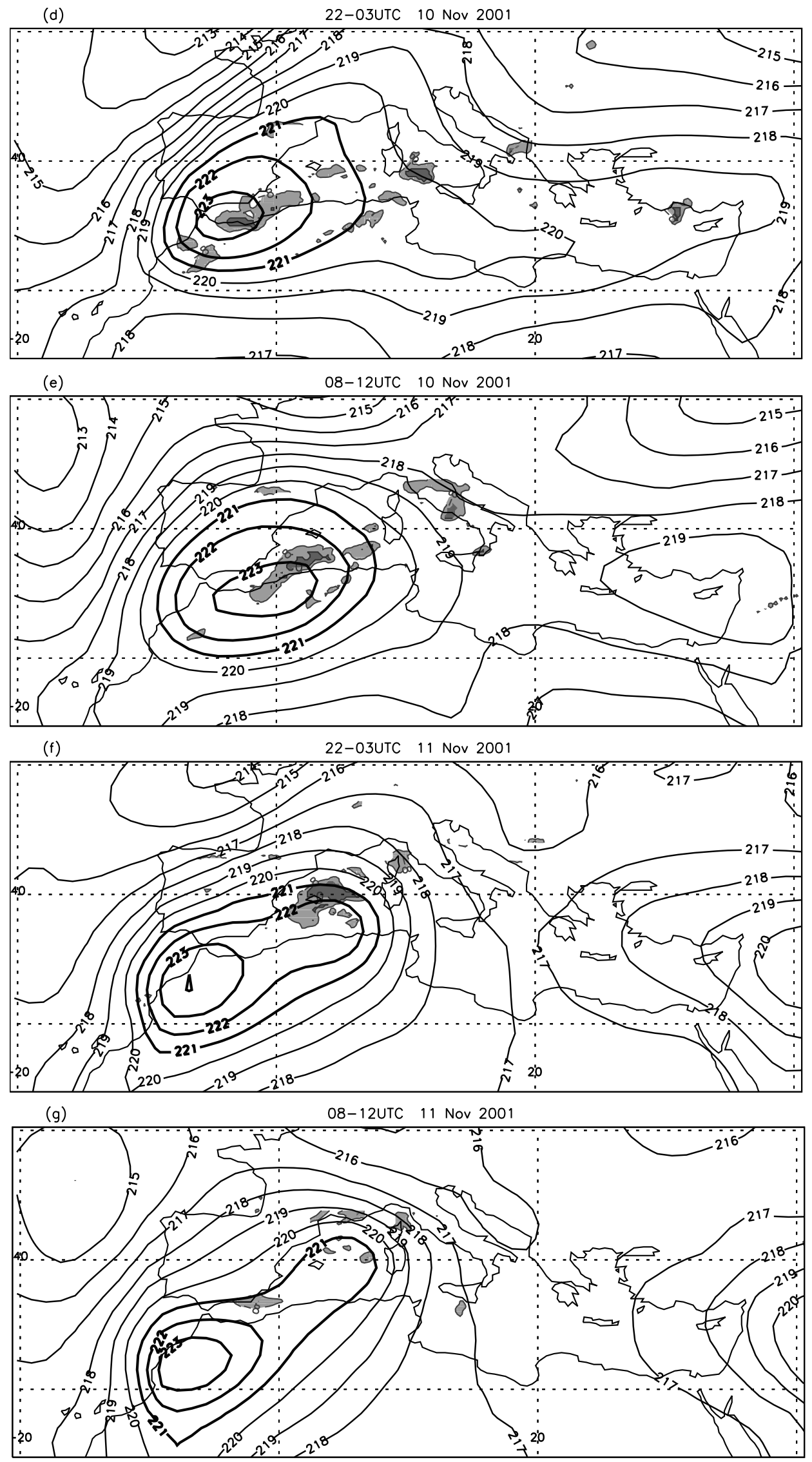

Figure 11. (continued) 

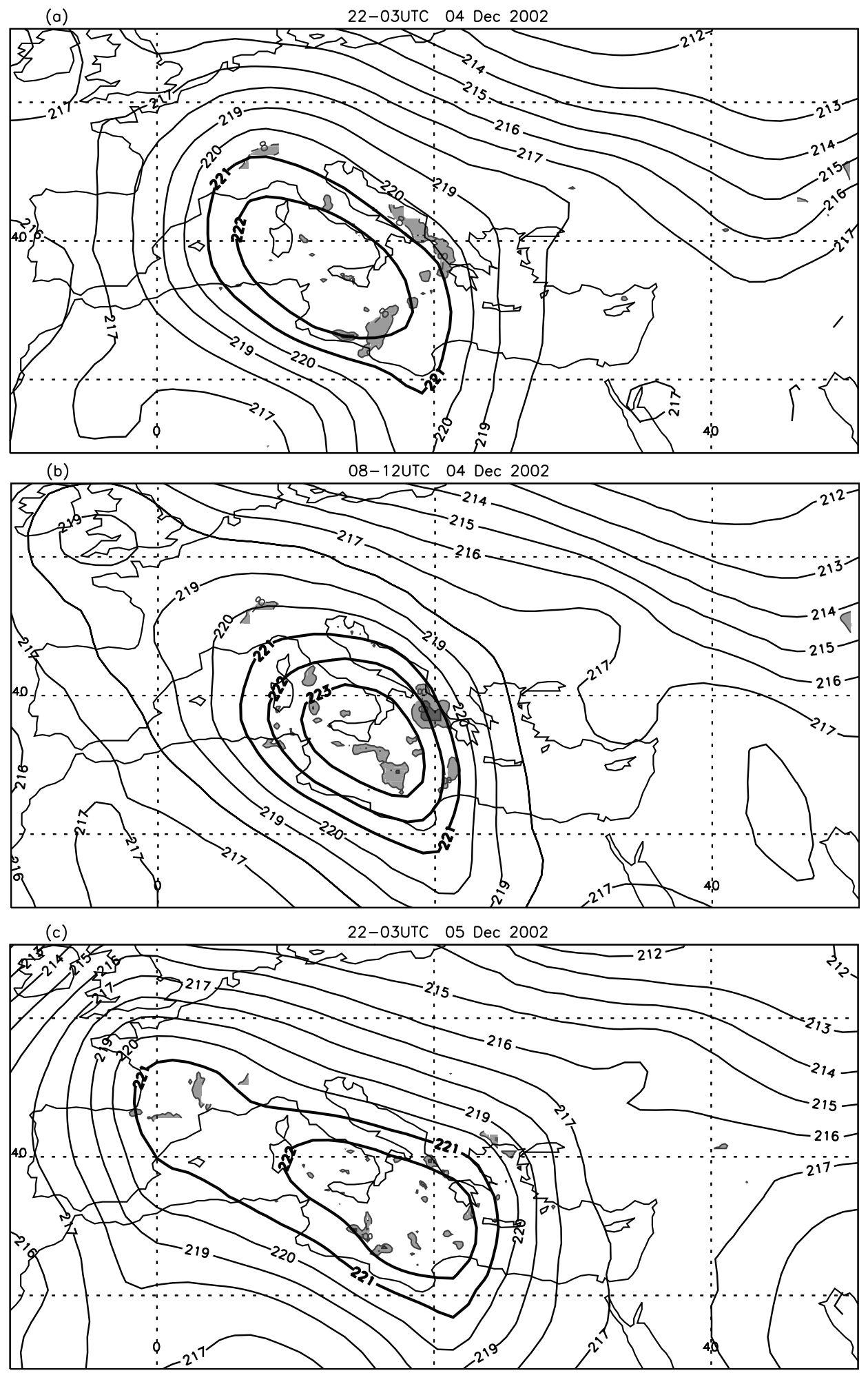

Figure 12. Same as Figure 11, except (a), (c), (e) descending (22-03 UTC), and (b), (d), (f) ascending (8-13 UTC) NOAA-16 passes, for 4-6 December 2002. 

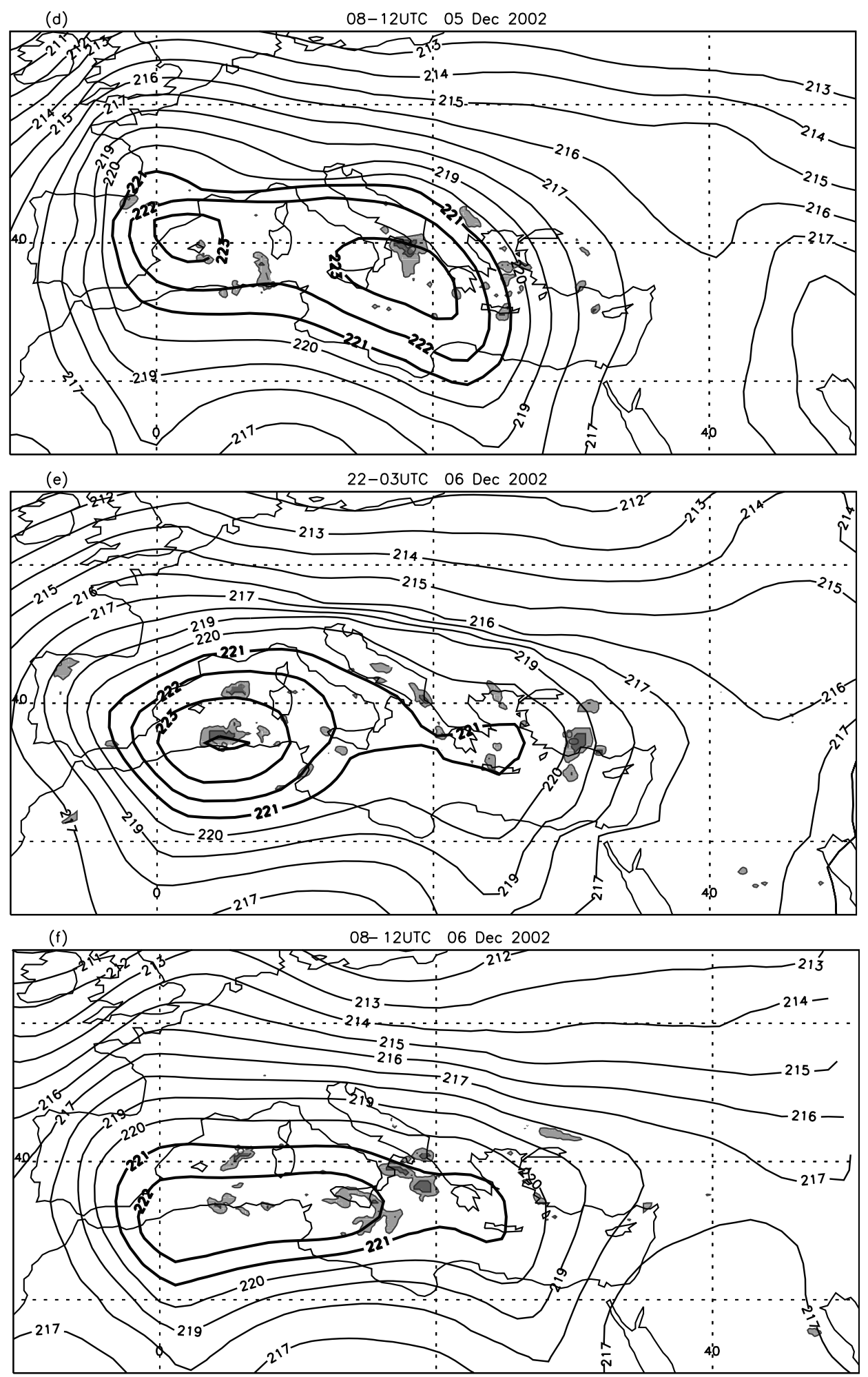

Figure 12. (continued)

region, and AMSU-B to detect moderate to intense precipitation. Because of its improved horizontal resolution relative to TOVS, AMSU data is attractive for characterization of weather systems in the Mediterranean, since these are most commonly in the sub-synoptic scale [e.g., Trigo et al., 1999; Chaboureau and Claud, 2006]. We focused on a number of case studies that produced heavy precipitation amounts. In all cases, a strong upper level (300-250 hPa)
PV intrusion signature was observed prior and during these events.

[46] We found that both $\mathrm{A} 8$ and $\mathrm{A} 7 \mathrm{~m} 5$ can detect upper level PV intrusions. However, A8 performs better than the combination of channels especially if the intrusion is shallow. Furthermore, higher A8 BT are observed as the maximum PV increases. A necessary (although not sufficient) condition to identify a PV greater than 4 PVU at 
$250 \mathrm{hPa}$ is that the $\mathrm{A} 8 \mathrm{BT}$ is at least $221 \mathrm{~K}$. When very strong stratospheric intrusions are present, this condition was found not to be effective enough to isolate the PV intrusion. A7m5 further documents the intrusion depth, a value greater than $-20 \mathrm{~K}$ indicating deeper intrusion. Slight modifications in the initial PV fields in numerical models can affect the intensity and location of precipitation forecast, as shown, e.g., by Argence et al. [2006] for high-resolution simulations of the Algiers storm. The results presented here indicate that assimilation of A8 BT at full resolution might improve short-term forecast.

[47] Concerning the discrimination of precipitation using AMSU-B we observed that although tropical DCT is able to detect heavily precipitating areas, it leaves out large regions where there was $3-\mathrm{h}$ accumulated rainfall of at least $10 \mathrm{~mm}$. We found that differences between channels 3 to 5 give a good qualitative agreement with TRMM 3B42 rain product and ground station data. In particular, $\mathrm{B} 3 \mathrm{~m} 5$ gave the most quantitatively consistent result, yielding a threshold of $-8 \mathrm{~K}$ to detect accumulated precipitation of at least $10 \mathrm{~mm} / 3 \mathrm{~h}$. This result was obtained for areas outside the Alps, the Pyrenees and the mountainous regions around the Black Sea, which were found to be problematic due to the high elevation and presence of snow. Therefore for future studies we will use the additional information of snow depth from, e.g., ERA-40 to filter out possible contamination from snow on the ground. The validity of the tropical DCT for the Mediterranean region was also examined here. We found that this criterion is able to isolate areas that can produce accumulated rainfall of more than $20 \mathrm{~mm} / 3 \mathrm{~h}$ in approximately $50 \%$ of the cases. One caveat in the analysis of precipitation is that TRMM data and AMSU-B data are not completely independent. However, our results were supported with comparison with independent ground data, and shown to be fairly robust.

[48] Finally, we used these channels and combinations of channels to depict two severe storm events: Algiers and Antalya. With A8 it was possible to follow the evolution of the upper level disturbance representing a high-PV trough, and with $\mathrm{B} 3 \mathrm{~m} 5$ and DCT the associated areas of precipitation and occurrence of deep convection. Such diagnostics can be used in real time for forecast purposes and for model verification as in, for example, Chaboureau and Pinty [2006] and Söhne et al. [2006].

[49] Finally, the above results were found based on data sets comprised between the months of September to December. Their dependency to seasonal variations should be small as the AMSU thresholds used here are based on channels nearly independent on the surface. In the case of precipitation, our method relies on the scattering of icy particles in cold clouds, which are more common in the cool season, but also exist in the summer season when convective clouds are present. Future work aims at further validation of these thresholds for other seasons and using these channels to establish a climatology of precipitating systems and their typology relative to the upper level situation, in a similar manner to Chaboureau and Claud [2006] for cloud systems.

[50] Acknowledgments. This study is part of and sponsored by the project CYPRIM (CYclognenèse et PRécipitation Intenses en région
Méditerranéenne). We thank Météo France for the SQR data and accumulated precipitation data for the case of Algiers, and Brice Boudevillain (LTHE) for accumulated rainfall and radar data used in this study. We thank also three anonymous reviewers for their insightful comments, as well as Fatima Karbou and Philippe Arbogast for fruitful discussions during the preparation of the manuscript. The TRMM and Other 3-hly accumulated rainfall data were acquired using the GES-DISC Interactive Online Visualization ANd aNalysis Infrastructure (Giovanni) as part of the NASA's Goddard Earth Sciences (GES) Data and Information Services Center (DISC).

\section{References}

Alpert, P., B. U. Neeman, and Y. Shay-el (1990), Climatological analysis of Mediterranean cyclones using ECMWF data, Tellus, 42A, 65-77.

Alpert, P., U. Stein, and M. Tsidulko (1995), Role of sea fluxes and topography in eastern Mediterranean cyclogenesis, Global Atmos. Ocean Syst., 3, 55-79.

Alpert, P., I. Osetinsky, and B. Ziv (2004), Semi-objective classification for daily synoptic systems: Application to the eastern Mediterranean climate change, Int. J. Climatol., 24, 1001-1011.

Appenzeller, C., and H. C. Davies (1992), Structure of stratospheric intrusions into the troposphere, Nature, 358, 570-572.

Appenzeller, C., H. C. Davies, and W. A. Norton (1996), Fragmentation of stratospheric intrusions, J. Geophys. Res., 101(D1), 1435-1456.

Argence, S., D. Lambert, E. Richard, N. Söhne, J.-P. Chaboureau, F. Crépin, and P. Arbogast (2006), High resolution numerical study of the Algiers 2001 flash flood: Sensitivity to the upper-level potential vorticity anomaly, Adv. Geosci., 7, 251-257.

Bauer, P., E. Moreau, F. Chevallier, and U. O'Keeffe (2006), Multiplescattering microwave radiative transfer for data assimilation applications, Q. J. R. Meteorol. Soc., 132, 1259-1281.

Bennartz, R., A. Thoss, A. Dybbroe, and D. B. Michelson (2002), Precipitation analysis using the Advanced Microwave Sounding Unit in support of nowcasting applications, Meteorol. Appl., 9, 177-189, doi:10.1017/S1350482702002037.

Buehler, S. A., M. Kuvatov, and V. O. John (2005), Scan asymmetries in AMSU-B data, Geophys. Res. Lett., 32, L24810, doi:10.1029/ 2005GL024747.

Brueske, K. F., and C. S. Velden (2003), Satellite-based tropical cyclone intensity estimation using the NOAA-KLM series Advanced Microwave Sounding Unit (AMSU), Mon. Wea. Rev., 131, 687-697.

Burns, B. A., X. Wu, and G. R. Diak (1997), Effects of precipitation and cloud ice on brightness temperatures in AMSU moisture channels, IEEE Trans. Geosci. Remote Sens., 35, 1429-1437.

Chaboureau, J.-P., and C. Claud (2006), Satellite-based climatology of Mediterranean cloud systems and their association with large-scale circulation, J. Geophys. Res., 111, D01102, doi:10.1029/2005JD006460.

Chaboureau, J. P., and J.-P. Pinty (2006), Validation of a cirrus parameterization with Meteosat Second Generation observations, Geophys. Res. Lett., 33, L03815, doi:10.1029/2005GL024725.

Deeter, M. N., and J. Vivekanandan (2005), AMSU-B observations of mixed-phase clouds over land, J. Appl. Meteorol., 44, 72-85.

Delrieu, G., et al. (2005), The catastrophic flash-flood event of 8-9 September 2002 in the Gard Region, France: A first case study for the CévennesVivarais Mediterranean Hydrometeorological Observatory, J. Hydrometeorol., 6, 34-52.

Fita, L. I., R. Romero, and C. Ramis (2006), Intercomparison of intense cyclogenesis events over the Mediterranean basin based on baroclinic and diabatic influences, $A d v$. Geosci., 7, 333-342.

Frei, C., and C. Schär (1998), A precipitation climatology of the alps from high-resolution rain-gauge observations, Int. J. Climatol., 18, $873-900$.

Goldberg, M. D., and H. E. Fleming (1995), An algorithm to generate deeplayer temperatures from microwave satellite observations for the purpose of monitoring climate change, J. Climate, 8, 993-1004.

Goldberg, M. D., D. S. Crosby, and L. Whou (2001), The limb adjustment of AMSU-A observations: Methodology and validation, J. Appl. Meteorol., $40,70-83$.

Greenwald, T. J., and S. A. Christopher (2002), Effect of cold clouds on satellite measurements near $183 \mathrm{GHz}$, J. Geophys. Res., 107(D13), 4170, doi:10.1029/2000JD000258.

Hong, G., G. Heygster, J. Miao, and K. Klaus (2005), Detection of tropical deep convective clouds from AMSU-B vapour channels measurements, J. Geophys. Res., 110, D05205, doi:10.1029/2004JD004949.

Kidder, S. Q., M. D. Goldberg, R. M. Zehr, M. DeMaria, J. F. W. Purdom, C. S. Velden, N. C. Grody, and S. J. Kusselson (2000), Satellite analysis of tropical cyclones using the advanced microwave sounding unit (AMSU), Bull. Am. Meteorol. Soc., 81(6), 1241-1259.

Kongoli, C., P. Pellegrino, R. R. Ferraro, N. C. Grody, and H. Meng (2003), A new snowfall detection algorithm over land using measurements from 
the Advanced Microwave Sounding Unit (AMSU), Geophys. Res. Lett., 30(14), 1756, doi:10.1029/2003GL017177.

Kotroni, V., K. Lagouvardos, E. Defer, S. Dietrich, F. Porcù, C. M. Medaglia, and M. Demirtas (2006), The Antalya 5 December 2002 storm: Observations and model analysis, J. Appl. Meteorol. Climatol., 45, 576590 .

Krichak, S. O., P. Alpert, and D. Melina (2004), The role of atmospheric processes associated with Hurricane Olga in the December 2001 floods in Israel, J. Hydrometeorol., 5, 1259-1270.

Langland, R. H. (2005), Observation impact during the North Atlantic TReC-2003, Mon. Wea. Rev., 133, 2297-2309.

Le Marshall, J., et al. (2006), Improving global analysis and forecasting with AIRS, Bull. Am. Meteorol. Soc., 87, 891-894.

Liniger, M. A., and H. C. Davies (2003), Substructure of a MAP streamer, Q. J. R. Meteorol. Soc., 129, 633-651.

Liu, Q. H., and F. Z. Weng (2003), One-dimensional variational retrieval algorithm of temperature, water vapor, and cloud water profiles from Advanced Microwave Sounding Unit (AMSU), IEEE Trans. Geosci. Remote Sens., 43, 1087-1095.

Massacand, A. C., H. Wernli, and H. C. Davies (1998), Heavy precipitation on the Alpine southside: An upper-level precursor, Geophys. Res. Lett., 79, 2059-2077.

Mo, T. (1999), AMSU-A antenna pattern corrections, IEEE Trans. Geosci. Remote Sens., 37, 103-112.

Moisselin, H. M., M. Schneider, C. Canellas, and O. Mestre (2002), Les changements climatiques en France au 20ème siècle: Etude des longues séries homogénéisées de données de température et de précipitations, Météorologie, 38, 45-56.

Moore, R. W., and T. H. Vonder Haar (2003), Diagnosis of a polar low warm core utilizing the Advanced Microwave Sounding Unit, Wea. Forecasting, 18, 700-711.

Moore, S. A., C. Wilson, and S. Bell (2005), High resolution modelling of the extreme precipitation event over Algiers in November 2001, Adv Geosci., 2, 139-143.

Prigent, C., F. Chevallier, F. Karbou, P. Bauer, and G. Kelly (2005), AMSUA land surface emissivity estimation for numerical weather prediction assimilation schemes, J. Appl. Meteorol., 44, 416-426, doi:10.1175/ JAM2218.1
Qiu, S., P. Pellegrino, R. Ferraro, and L. M. Zhao (2005), The improved AMSU rain-rate algorithm and its evaluation for a cool season event in the western United States, Wea. Forecasting, 20, 761-774.

Saunders, R. W., M. Matricardi, P. Brunel, S. English, P. Bauer, U. O'Keeffe, P. Francis, and P. Rayer (2005), RTTOV-8 science and validation report, technical report, 41 pp. , Numer. Weather Predic. Satell. Appl. Facil. Exeter, U. K.

Söhne, N., J.-P. Chaboureau, S. Argence, D. Lambert, and E. Richard (2006), Objective evaluation of mesoscale simulations of the Algiers 2001 flash flood by the model-to-satellite approach, Adv. Geosci., 7, $247-250$

Trigo, I. F., T. D. Davies, and G. R. Bigg (1999), Objective climatology of cyclones in the Mediterranean region, J. Climate, 12, 1685-1696.

Tripoli, G. J., C. M. Medaglia, S. Dietrich, A. Mugnai, G. Panegrossi, S. Pinori, and E. A. Smith (2005), The 9-10 November 2001 Algerian Flood, A numerical study, Bull. Am. Meteorol., 1229-1235.

Uppala, S. M., et al. (2005), The ERA-40 re-analysis, Q. J. R. Meteorol. Soc., 131, 2961-3012.

Wark, D. Q. (1993), Adjustment of TIROS Operational Vertical Sounder data to a vertical view. NOAA Tech. Rep. NESDIS-64, $36 \mathrm{pp}$

Weng, F., L. Zhao, R. R. Ferraro, G. Poe, X. Li, and N. C. Grody (2003), Advanced microwave sounding unit cloud and precipitation algorithms, Radio Sci., 38(4), 8068, doi:10.1029/2002RS002679.

Zhao, Y., B. Wang, Z. Z. Ji, X. D. Liang, G. Deng, and X. Zhang (2005), Improved track forecasting of a typhoon reaching landfall from fourdimensional variational data assimilation of AMSU-A retrieved data, J. Geophys. Res., 110, D14101, doi:10.1029/2004JD005267.

Zhu, T., D. L. Zhang, and F. Z. Weng (2002), Impact of the advanced microwave sounding unit measurements on hurricane prediction, Mon Wea. Rev., 130, 2416-2432.

J.-P. Chaboureau, Laboratoire d'Aérologie, Observatoire Midi-Pyrénées, 14 avenue Belin, 31400 Toulouse, France. (jean-pierre.chaboureau@ aero.obs-mip.fr)

C. Claud and B. M. Funatsu, Laboratoire de Meteorologie Dynamique/ IPSL, Ecole Polytechnique, 91128 Palaiseau CEDEX, France. (chantal. claud@lmd.polytechnique.fr; funatsu@lmd.polytechnique.fr) 